\title{
Load Characteristics in Taylor Impact Test on Projectiles with Various Nose Shapes
}

\author{
Jun-Cheng Li ${ }^{1,2}$, Gang Chen ${ }^{2, *}$, Feng-Lei Huang ${ }^{1}$ and Yong-Gang Lu ${ }^{2}$ \\ 1 State Key Laboratory of Explosion Science and Technology, Beijing Institute of Technology, \\ Beijing 100081, China; 3120160071@bit.edu.cn (J.-C.L.); huangfl@bit.edu.cn (F.-L.H.) \\ 2 Institute of Systems Engineering, China Academy of Engineering Physics, Mianyang 621999, China; \\ lygcaep@263.net \\ * Correspondence: chengang@caep.cn
}

Citation: Li, J.-C.; Chen, G.; Huang,

F.-L.; Lu, Y.-G. Load Characteristics in Taylor Impact Test on Projectiles with Various Nose Shapes. Metals 2021, 11, 713. https://doi.org/10.3390/ met11050713

Academic Editor: Ronald W. Armstrong

Received: 19 March 2021

Accepted: 22 April 2021

Published: 27 April 2021

Publisher's Note: MDPI stays neutral with regard to jurisdictional claims in published maps and institutional affiliations.

Copyright: (c) 2021 by the authors. Licensee MDPI, Basel, Switzerland. This article is an open access article distributed under the terms and conditions of the Creative Commons Attribution (CC BY) license (https:// creativecommons.org/licenses/by/ $4.0 /)$.

\begin{abstract}
This study focused on the impact load produced by a projectile and its potential application in the Taylor impact test. Taylor impact tests were designed and carried out for projectiles with four types of nose shapes, and the impact deformation characteristics and variation of the impact load as a function of the nose shape and impact velocity were studied. The overall high $g$ loading experienced by the projectile body during the impact was discussed, and based on classical Taylor impact theory, impact analysis models for the various nose-shape projectiles were established and the causes of the different impact load pulse shapes were analyzed. This study reveals that the nose shape has a significant effect on the impact load waveform and pulse duration characteristics, while the impact velocity primarily affects the peak value of the impact load. Thus, the loading of specific impact environments could be regulated by the projectile nose shape design and impact velocity control, and the impact load could be simulated. Research results support the assumption that the Taylor impact test can be applied to high $g$ loading test.
\end{abstract}

Keywords: Taylor impact test; nose shape; impact load; high $g$ loading; waveform and pulse duration; theoretical analysis model

\section{Introduction}

In the process of a precision attack on targets, the internal electronic equipment (i.e., intelligent fuses, missile borne recording devices, etc.) of advanced penetration weapons typically experience impacts that are several milliseconds in duration and tens of thousands of $g\left(g=9.8 \mathrm{~m} / \mathrm{s}^{2}\right)$ in magnitude. To improve the reliability of onboard electronic equipment, targeted impact tests must be conducted in the development and production stages to assess their survivability and working performance in high-impact environments. Currently, under laboratory conditions, the main simulation methods of high-impact environments include the Machete hammer test, the Split-Hopkinson pressure bar (SHPB), and the drop tower test. However, these methods can typically provide only a small impact energy, a short acceleration duration, and the test piece size is generally limited to dozens of grams, which is difficult to apply in the assessment of subsystem and component products with a large mass. Live ammunition can provide a real impact environment, but it entails high cost, long cycles, small sample numbers, and poor repeatability, making them unsuitable for many research tests. Therefore, it is necessary to explore a new high $g$ loading impact test method that has large impact energy as well as a low test cost and can provide the required impact environment for anti-impact assessment of onboard electronic equipment under laboratory conditions.

The Taylor impact test method was established by Taylor and Whiffin to measure the dynamic yield stress of materials under high strain rate conditions [1,2]. During the test, a blunt cylindrical projectile comprised of a particular material is vertically impacted on a rigid target surface, and the dynamic yield stress of the material is obtained by 
measuring the external dimensions of the recovered deformed projectile. The method is simple and convenient for analysis. In addition to being widely used in the study of the dynamic mechanical behavior of metallic materials at high strain rates [3-6], the Taylor impact test is also used in the research of polymer materials, foam metals, glass, and other materials [7-10]. Since the Taylor impact test can easily realize large deformations, high strain rates $\left(10^{4}-10^{7} \mathrm{~s}^{-1}\right)$, and large temperature increases, it is often used to verify the constitutive model [11-14]. Since the Taylor impact test was introduced, researchers have been constantly refining it, including applying stereo digital image correlation (DIC) technology to measure the strain field [15], introducing a symmetric Taylor impact test to eliminate the assumption of regarding the target as an ideally rigid material [16], using the Taylor impact test to measure the stress-strain curves of the materials [17], and so on.

Currently, research using the Taylor impact test primarily focuses on acquiring constitutive material parameters and damage model verification, while little attention is paid to the impact load and its application. The Taylor impact test itself is characterized by high impact energy, low cost, and good repeatability, giving it the technical foundation and development potential for application in high $g$ loading. In the classical Taylor impact test, where a blunt projectile is impacted on a rigid target, the pulse shape of the impact is usually trapezoidal, and the test cannot generate shock loading with a specific pulse shape; thus, it is greatly limiting in the engineering application. In the SHPB test [18], the shape of the incident wave is controlled in two ways: one is by adding a waveform shaper at the impact end, and the other is by using bullets with a special shape designed to obtain the required incident waveform [19]. In the latter, the waveform indicating the duration of the load generated by the impact can be adjusted by changing the nose shape of the projectile. Therefore, the investigation of the relationship between the impact deformation of specimens with different nose shapes and the impact load characteristics in the Taylor impact test is important, which is beneficial to control and adjust the impact load characteristics generated by the impact and make it closer to the real load in the engineering application.

On the basis of the above research purpose, a combined Taylor-Hopkinson impact test of projectiles with four typical nose shapes was designed and carried out. In the test, highspeed photography was used to record the deformation of the specimen during the impact process, in which the Hopkinson incident bar was used as the impact target. According to the principle of a one-dimensional stress wave, the load history of the impact end was obtained through the strain signal on the incident bar. The impact deformation characteristics of the projectiles with different nose shapes were examined, and the dependencies of the impact load with the specimen nose shape and impact velocity were analyzed and compared. Different from the research works on the ballistic behavior of projectiles with various nose shapes, this study mainly focused on the load characteristics produced by the impact, and the overall high $g$ overload experienced by the projectile during the impact process was discussed. Finally, based on the classical Taylor impact theory, a Taylor impact theoretical analysis model of the different projectile nose shapes was established, and the cause of the varying pulse shapes of the impact loads was analyzed.

\section{Experimental System}

\subsection{The Size and Material of Projectile}

According to the research purpose, projectiles with four types of nose shapes were designed. In addition to the blunt projectile typically used in the classical Taylor impact test, hemispherical, truncated ogive, and truncated conical projectiles were employed (Figure 1). The projectiles had a diameter of $\varnothing 25 \mathrm{~mm}$, and the length of the blunt projectile was $100 \mathrm{~mm}$. The length of the cylindrical segment of the other three projectiles was designed to ensure the equal mass $(0.134 \mathrm{~kg})$ of all types. Therefore, the total length of the hemispherical projectile was $104.1 \mathrm{~mm}$. For the truncated ogive projectile, the curve diameter ratio was 3, the top diameter was $\varnothing 5 \mathrm{~mm}$, and the total length was $114.9 \mathrm{~mm}$. Finally, the cone angle of the truncated conical projectile was $30^{\circ}$, the top diameter was $\varnothing 5 \mathrm{~mm}$, and the total projectile length was $122 \mathrm{~mm}$. Figure 2 shows a photograph of the test projectiles. 


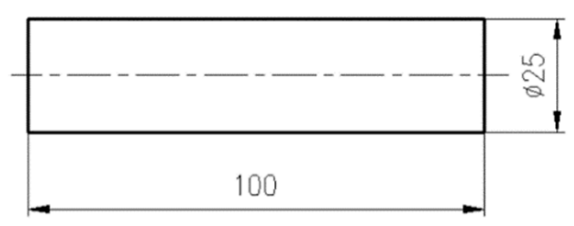

(a) Blunt

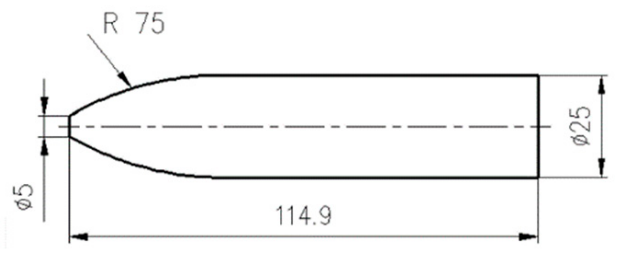

(c) Truncated ogive
R 12.5

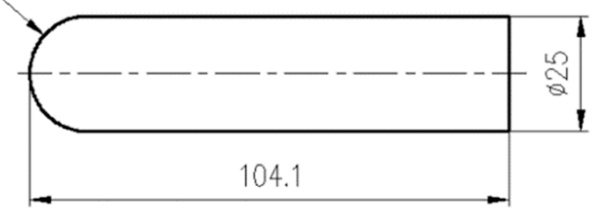

(b) Hemispherical

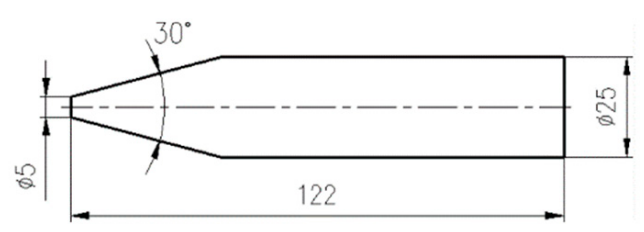

(d) Truncated conical

Figure 1. Structure diagrams of test projectiles (all values in $\mathrm{mm}$ ).

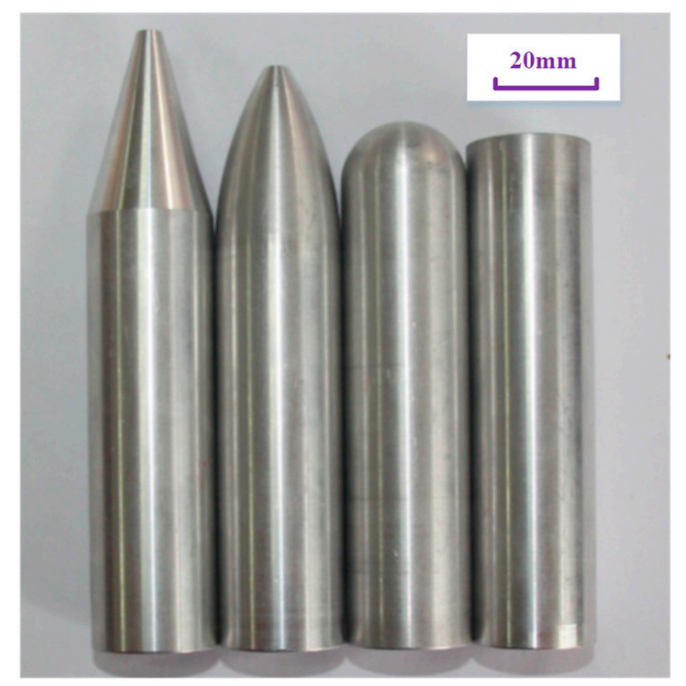

Figure 2. Photograph of (left to right) truncated conical, truncated ogive, hemispherical, and blunt projectiles.

The projectile material was 3A21 aluminum alloy, which possesses high plasticity in the annealed state. In order to understand the materials' mechanical properties and obtain their mechanical characteristic parameters, compression tests were carried out under quasi-static conditions $\left(8 \times 10^{-4} \mathrm{~s}^{-1}\right)$ and a high strain rate $\left(2.2 \times 10^{3} \mathrm{~s}^{-1}\right)$ on a material testing machine and SHPB. The specimen size was $10 \mathrm{~mm}$ diameter $\times 20 \mathrm{~mm}$ length in the quasi-static test and $10 \mathrm{~mm}$ diameter $\times 5 \mathrm{~mm}$ length in the SHPB test. A comparison of the engineering stress-strain curves under static and dynamic deformation conditions is shown in Figure 3. The stress-strain curves under dynamic conditions are essentially consistent with those under static conditions ( $\leq 5 \%$ variance), indicating that $3 \mathrm{~A} 21$ aluminum alloy is insensitive to the strain rate. On the basis of the plastic volume invariance principle, the quasi-static compressive stress-strain curve of the material was transformed into a true stress-strain curve, and the latter is plotted in Figure 4. 


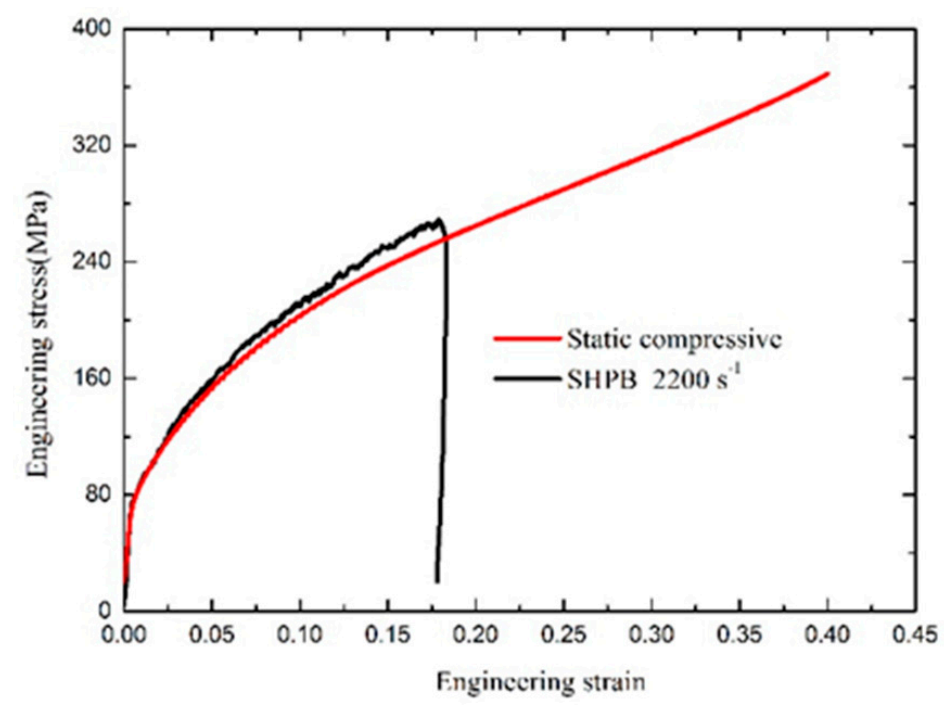

Figure 3. Static (red) and dynamic (black) engineering stress-strain curves of 3A21 aluminum alloy.

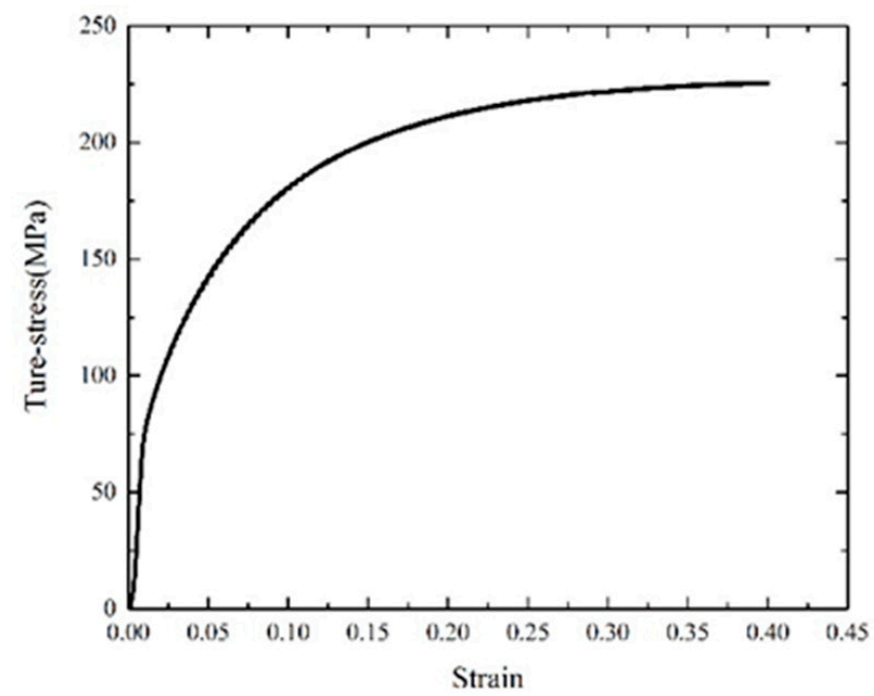

Figure 4. True stress-strain curve of 3A21 aluminum alloy.

\subsection{Test Device}

In previous reports by Li et al. [20], Liu et al. [21], and Wang et al. [22] comprising dynamic mechanical property studies of foam metal, the rigid impact target of the Taylor impact test was replaced with the Hopkinson incident bar. The bar stiffness is much higher than that of the blunt projectile, preventing the incident bar from undergoing plastic deformation during the impact process. In their works, the strain signal of the incident bar was recorded by a measuring instrument, and the impact force of the impacted projectile end was measured by the strain output signal of the incident bar.

With reference to these test methods, the test system herein comprised an air gun, a projectile, a laser velocimeter, a digital high-speed camera, a Hopkinson incident bar, and the strain test system. A schematic (Figure 5) and photograph (Figure 6) of the overall test system layout are shown. The inner diameter of the air gun was $\varnothing 25 \mathrm{~mm}$, and the good fit between the projectile and air gun was realized by the dimension tolerance. The Hopkinson incident bar was $3 \mathrm{~m}$ long with a $\varnothing 50 \mathrm{~mm}$ diameter and was comprised of 7A04 high-strength aluminum alloy material, whose primary parameters of the mechanical properties are shown in Table 1. The chemical compositions of the material for projectile and incident bar are presented in Table 2. Two strain gauges were mounted on the middle of the incident bar, diametrically opposed to each other, to measure the strain during 
impact, where the sampling frequency of the strain measurement system was $10 \mathrm{MHz}$. Two parallel laser beams were placed at the exit end of the launch tube to measure the velocity of the projectile. The deformation of the projectile during impact was recorded by a high-speed digital camera, at an amplitude frequency of 50,000 frames/s, (i.e., one image acquired every $20 \mu \mathrm{s}$ ). For observational convenience, background grid paper with $11 \mathrm{~mm} \times 11 \mathrm{~mm}$ grid size was mounted behind the impact area field of view.

\section{Background Board}

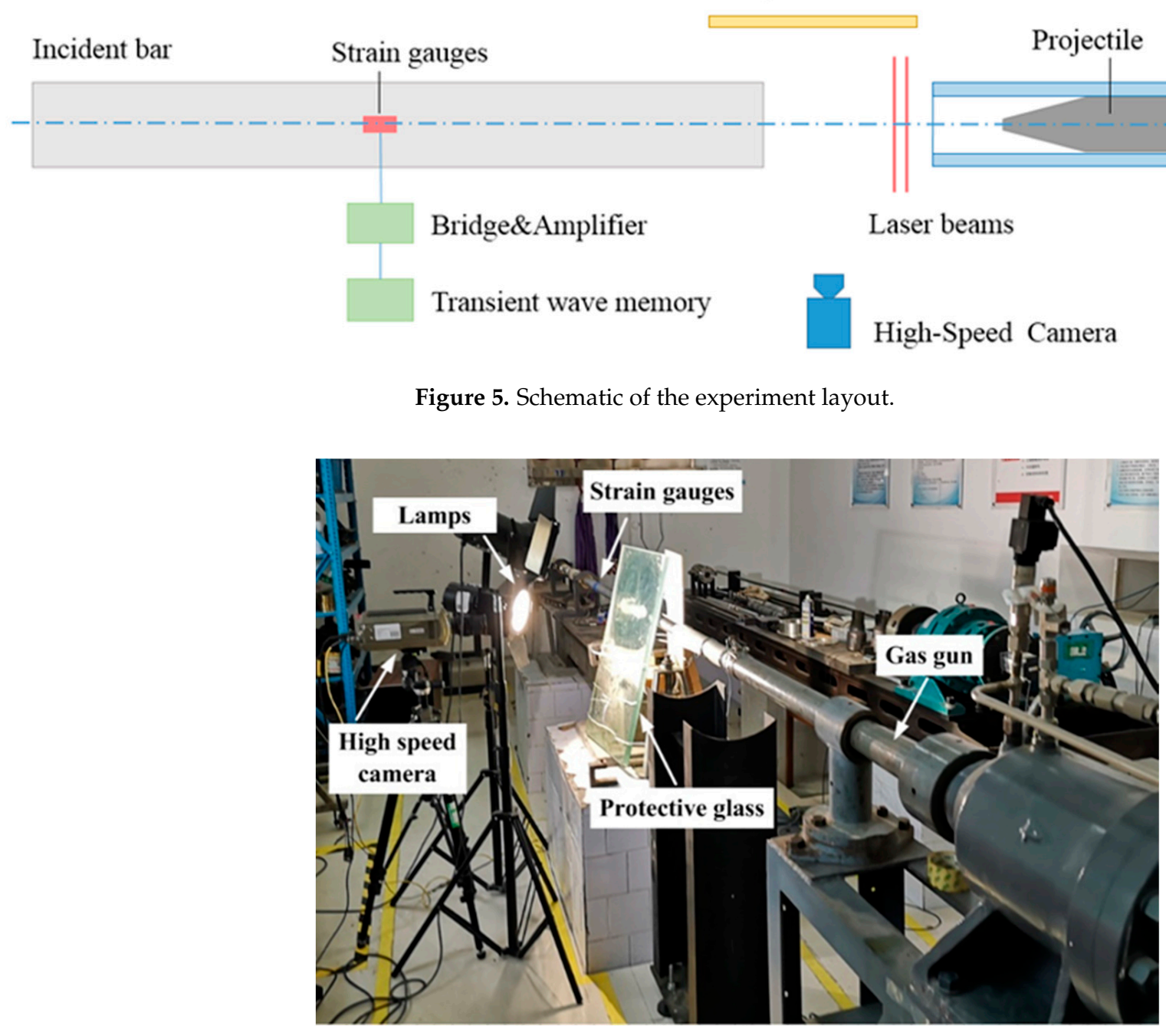

Figure 6. Photograph of the experiment layout.

Table 1. Primary mechanical property parameters of materials.

\begin{tabular}{cccccc}
\hline Material & Density/(kg $\left.\mathbf{m}^{-\mathbf{3}}\right)$ & Elastic Modulus/GPa & Yield Strength/MPa & Tensile Strength/MPa & Poission Ratio \\
\hline 3A21 & 2730 & 71 & 80 & 226 & 0.31 \\
7A04 & 2810 & 72 & 400 & 550 & 0.33 \\
\hline
\end{tabular}

Table 2. Chemical compositions of the aluminum alloys (wt \%).

\begin{tabular}{ccccccccc}
\hline Material & Si & Fe & Cu & Mn & Mg & Cr & Zn & Ti \\
\hline 3A21 & 0.6 & 0.7 & 0.2 & 1.3 & 0.05 & - & 0.1 & 0.15 \\
7A04 & 0.5 & 0.5 & 1.7 & 0.4 & 2.3 & 0.175 & 6.0 & 0.1 \\
\hline
\end{tabular}


To prevent plastic deformation of the incident bar under multiple impacts and ensure that each experiment encountered an impact surface in the same state, a cushion block of the same material and diameter as the incident bar was placed on the impact end of the incident bar and replaced after each test.

\section{Test Results and Analysis}

A total of 28 rounds of experiments were carried out, wherein each of the four types of nose-shape projectiles was tested seven times with impact velocities ranging from 50 to $220 \mathrm{~m} / \mathrm{s}$. The specific information and results of each test are summarized in Table 3 , where $m$ is the projectile mass; $L_{0}$ is the initial projectile length; $D_{i}$ is the initial nose diameter; $D_{c}$ is the projectile cylindrical segment diameter; $v_{0}$ is the impact velocity; $L_{f}$ and $D_{f}$ are the projectile residual length and top diameter recovered after the test, respectively; $F$ is the peak load produced by the impact; $\tau$ is the duration of loading; and $a_{p}$ is the peak acceleration, obtained by dividing the peak impact load by the projectile mass.

Table 3. Experiments information and results.

\begin{tabular}{|c|c|c|c|c|c|c|c|c|c|c|}
\hline Test No. & $\begin{array}{l}m \\
\mathrm{~kg}\end{array}$ & $\begin{array}{c}L_{0} \\
\mathrm{~mm}\end{array}$ & $\begin{array}{c}D_{i} \\
\mathrm{~mm}\end{array}$ & $\begin{array}{c}D_{c} \\
\mathrm{~mm}\end{array}$ & $\begin{array}{c}v_{0} \\
\mathrm{~m} / \mathrm{s}\end{array}$ & $\begin{array}{c}L_{f} \\
\mathbf{m m}\end{array}$ & $\begin{array}{c}D_{f} \\
\mathbf{m m}\end{array}$ & $\begin{array}{c}F \\
\mathbf{k N}\end{array}$ & $\begin{array}{c}\tau \\
\mu \mathrm{s}\end{array}$ & $\begin{array}{c}a_{p} \\
10^{4} g\end{array}$ \\
\hline P-1 & 0.134 & 100 & 25 & 25 & 58 & 97.75 & 26.04 & 116 & 116.7 & 8.8 \\
\hline P-2 & 0.134 & 100 & 25 & 25 & 90 & 95.28 & 27.25 & 152 & 142.9 & 11.6 \\
\hline P-3 & 0.134 & 100 & 25 & 25 & 98 & 94.52 & 27.71 & 156 & 145.7 & 11.9 \\
\hline P-4 & 0.134 & 100 & 25 & 25 & 140 & 90.51 & 30.28 & 192 & 156.9 & 14.6 \\
\hline P-5 & 0.134 & 100 & 25 & 25 & 168 & 86.12 & 33.74 & 225 & 175 & 17.1 \\
\hline P-6 & 0.134 & 100 & 25 & 25 & 170 & 85.61 & 34.28 & 228 & 179.6 & 17.4 \\
\hline P-7 & 0.134 & 100 & 25 & 25 & 171 & 85.46 & 34.51 & 232 & 183.2 & 17.7 \\
\hline Q-1 & 0.134 & 104.1 & - & 25 & 44 & 101.52 & 15.53 & 81.7 & 139.4 & 6.2 \\
\hline Q-2 & 0.134 & 104.1 & - & 25 & 86 & 97.37 & 20.76 & 113 & 155.5 & 8.6 \\
\hline Q-3 & 0.134 & 104.1 & - & 25 & 117 & 93.86 & 24.57 & 138.7 & 173.2 & 10.6 \\
\hline Q-4 & 0.134 & 104.1 & - & 25 & 133 & 91.72 & 25.51 & 134 & 184.9 & 10.2 \\
\hline Q-5 & 0.134 & 104.1 & - & 25 & 144 & 90.21 & 26.92 & 149.4 & 187.9 & 11.4 \\
\hline Q-6 & 0.134 & 104.1 & - & 25 & 178 & 86.22 & 29.81 & 181.3 & 215.2 & 13.8 \\
\hline Q-7 & 0.134 & 104.1 & - & 25 & 193 & 83.41 & 32.02 & 193 & 201.2 & 14.7 \\
\hline L-1 & 0.134 & 114.9 & 5 & 25 & 54 & 107.42 & 15.03 & 52 & 235.2 & 4 \\
\hline L-2 & 0.134 & 114.9 & 5 & 25 & 93 & 103.03 & 18.94 & 87 & 240.4 & 6.6 \\
\hline L-3 & 0.134 & 114.9 & 5 & 25 & 114 & 99.82 & 21.45 & 100 & 245.3 & 7.6 \\
\hline L-4 & 0.134 & 114.9 & 5 & 25 & 165 & 92.66 & 27.84 & 144 & 237.1 & 11 \\
\hline L-5 & 0.134 & 114.9 & 5 & 25 & 183 & 89.61 & 29.21 & 145 & 241.2 & 11 \\
\hline L-6 & 0.134 & 114.9 & 5 & 25 & 204 & 87.82 & 32.22 & 165 & 237.3 & 12.6 \\
\hline L-7 & 0.134 & 114.9 & 5 & 25 & 216 & 82.93 & 40.61 & 185 & 241.2 & 14.1 \\
\hline Z-1 & 0.134 & 122 & 5 & 25 & 60 & 112.35 & 13.18 & 42 & 319 & 3.2 \\
\hline Z-2 & 0.134 & 122 & 5 & 25 & 62 & 111.04 & 14.42 & 43 & 312 & 3.3 \\
\hline Z-3 & 0.134 & 122 & 5 & 25 & 125 & 101.28 & 22.28 & 105 & 291 & 8 \\
\hline Z-4 & 0.134 & 122 & 5 & 25 & 145 & 95.51 & 27.91 & 123 & 278 & 9.4 \\
\hline Z-5 & 0.134 & 122 & 5 & 25 & 170 & 92.61 & 29.13 & 136 & 275 & 10.4 \\
\hline Z-6 & 0.134 & 122 & 5 & 25 & 195 & 89.02 & 30.02 & 159 & 272 & 12.1 \\
\hline Z-7 & 0.134 & 122 & 5 & 25 & 199 & 88.62 & 34.31 & 160 & 276 & 12.2 \\
\hline
\end{tabular}

\subsection{Impact Deformation of Projectiles and Comparative Analyses}

Figure 7 shows a series of high-speed photographs of the blunt projectile at the impact velocity of $171 \mathrm{~m} / \mathrm{s}$. After the blunt projectile impacts the incident bar ( $t=0 \mu \mathrm{s})$, the nose is in close contact with the target surface, and the impact end surface is approximately flat. With the increasing impact time, the projectile begins to compress and deforms slightly. Owing to the obstruction of the target surface in the velocity direction, the material flows along the projectile radial direction. Thus, the cross-sectional area of the nose is expanded, a mushroom-shaped pier is formed at the impact end of the nose, and the front end of the projectile becomes flared in a bell shape. After $t=160 \mu \mathrm{s}$, the tail contour of the projectile 
can no longer move forward, the deformation of the pier diameter stops, and the plastic zone of the nose stops expanding. After $t=180 \mu \mathrm{s}$, the contour line of the projectile tail rebounds and moves backward, and the impact process is completed.
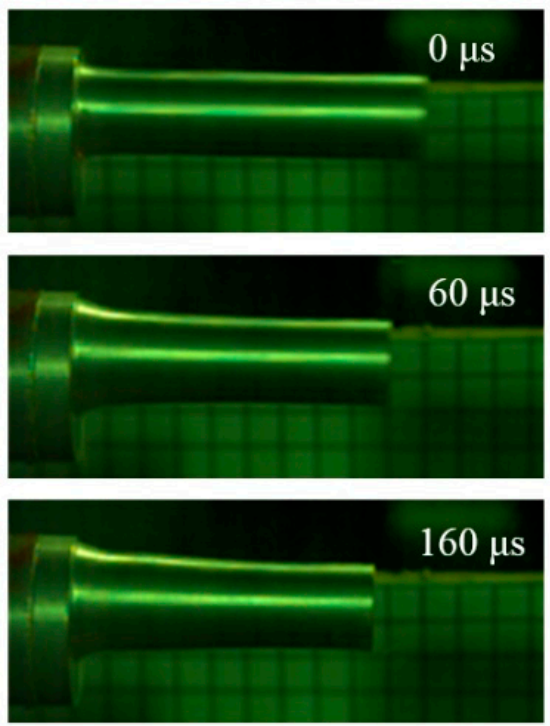
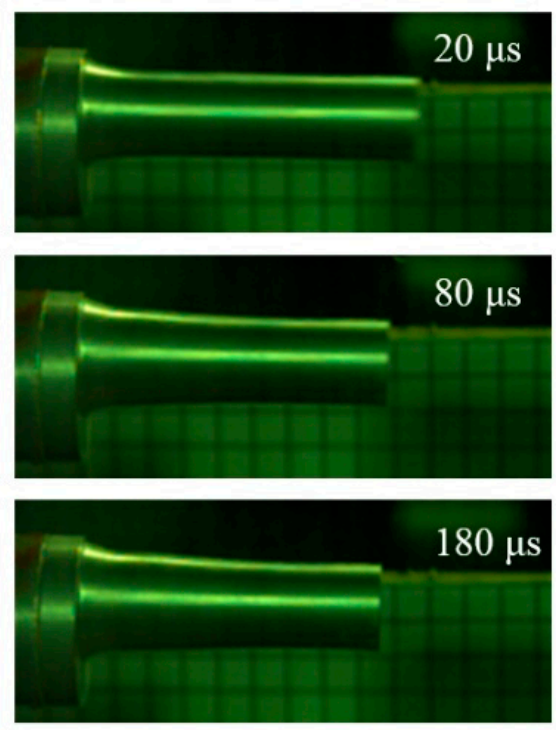
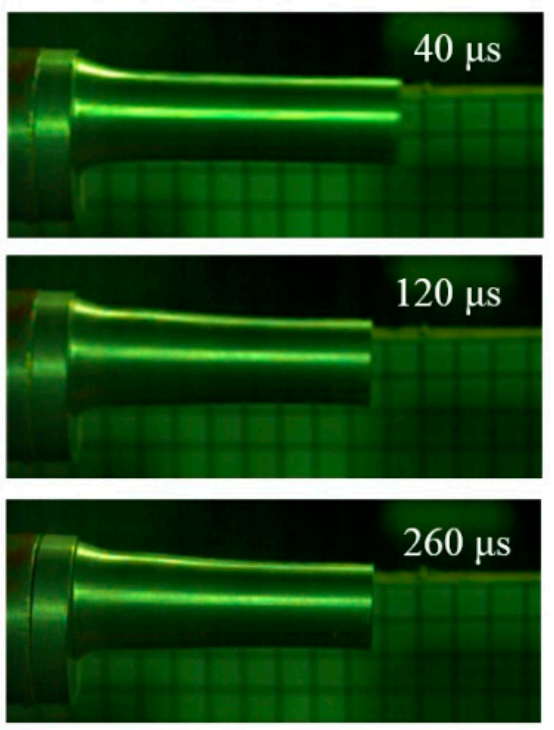

Figure 7. Series of high-speed photographs of the Taylor impact of the blunt projectile $(171 \mathrm{~m} / \mathrm{s})$.

Figure 8 shows a series of high-speed photographs of the hemispherical projectile at an impact velocity of $178 \mathrm{~m} / \mathrm{s}$. After the hemispherical nose projectile impacts the incident bar $(t=0 \mu \mathrm{s})$, the nose initially contacts the incident bar. Owing to the small contact area, there is impact fire at the initial moment of impact. Then, the nose is gradually compressed, and the material flows radially from the projectile, whereupon the contact area increases, and the impact surface is shaped like a flat spherical crown. After $t=200 \mu$ s, the projectile rebounds and moves backward, indicating the end of the impact process. The impact time of the hemispherical projectile is slightly longer than that of the blunt projectile, although the final deformation shapes are similar. From the side view, the front end of the deformed hemispherical projectile is also flared in a bell-like shape.

Figure 9 shows a series of high-speed photographs of the truncated ogive projectile at the impact velocity of $165 \mathrm{~m} / \mathrm{s}$. Similar to the blunt projectile, after the projectile impacts the incident bar $(t=0 \mu \mathrm{s})$, the end face is in close contact with the incident bar and gradually compresses and deforms, the material flows along the projectile radial direction, and the cross-sectional area of the nose expands. After $220 \mu$ s of impact, the tail contour of the projectile ceases to move forward; meanwhile after $240 \mu$ s the projectile rebounds and moves backward, indicating the end of the impact process. The duration of loading of the truncated ogive projectile is significantly longer than that of hemispherical and blunt projectiles.

Figure 10 shows a series of high-speed photographs of the truncated conical projectile at the impact velocity of $168 \mathrm{~m} / \mathrm{s}$. Similar to the truncated ogive projectile, after the projectile impacts the incident bar $(t=0 \mu \mathrm{s})$, the nose is compressed, and the section diameter is enlarged. When the diameter of the nose approaches or exceeds the projectile diameter, a pier thickness occurs at the junction of the nose and the cylinder and a "turning line" can be observed at the junction of the cone section and the cylinder section. At $280 \mu \mathrm{s}$ after impact, the projectile rebounds and moves backward, indicating the end of the impact process. The duration of loading of the truncated conical projectile is the longest among the four nose-shape types. 


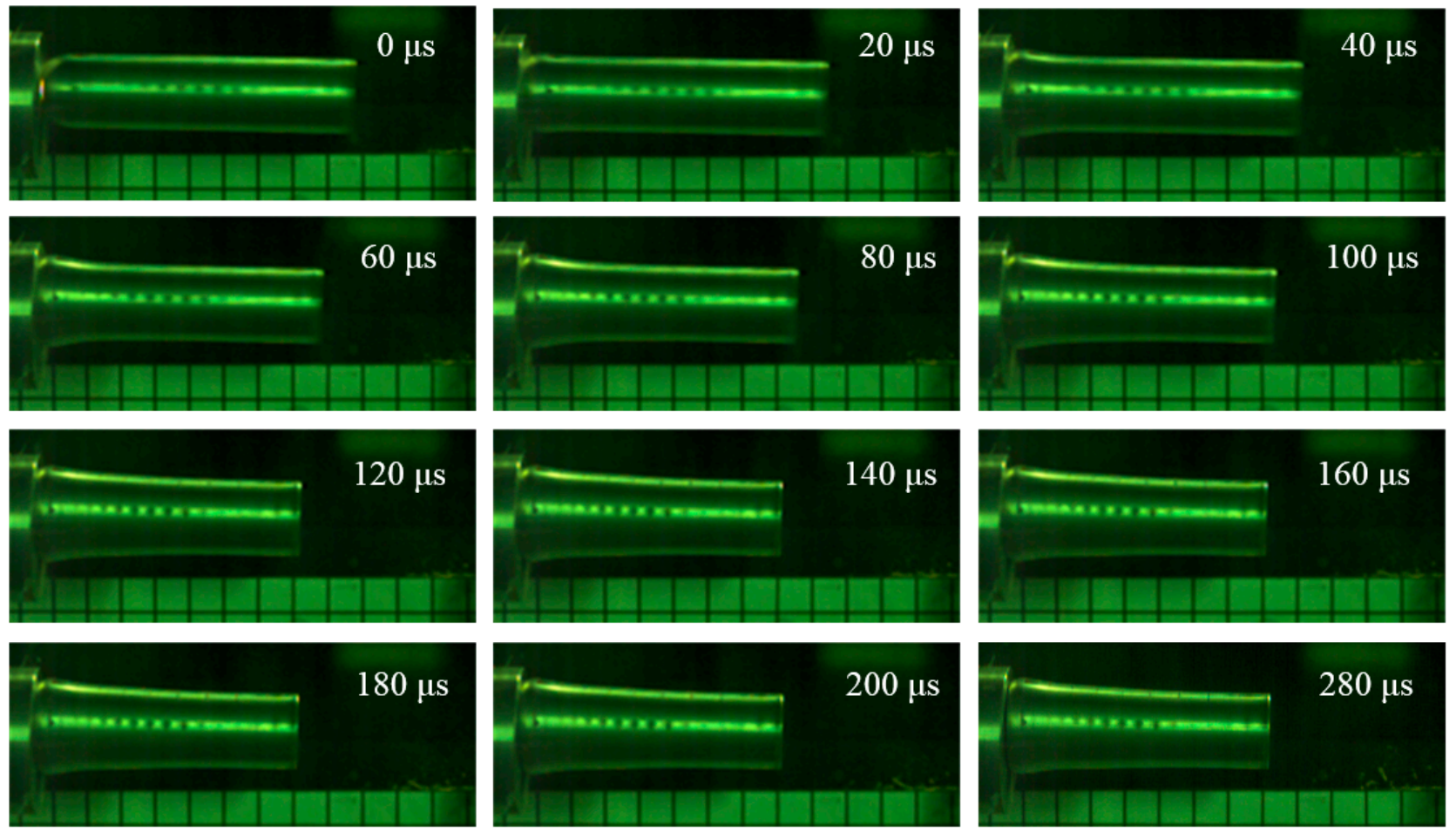

Figure 8. Series of high-speed photographs of the Taylor impact of the hemispherical projectile $(178 \mathrm{~m} / \mathrm{s})$.
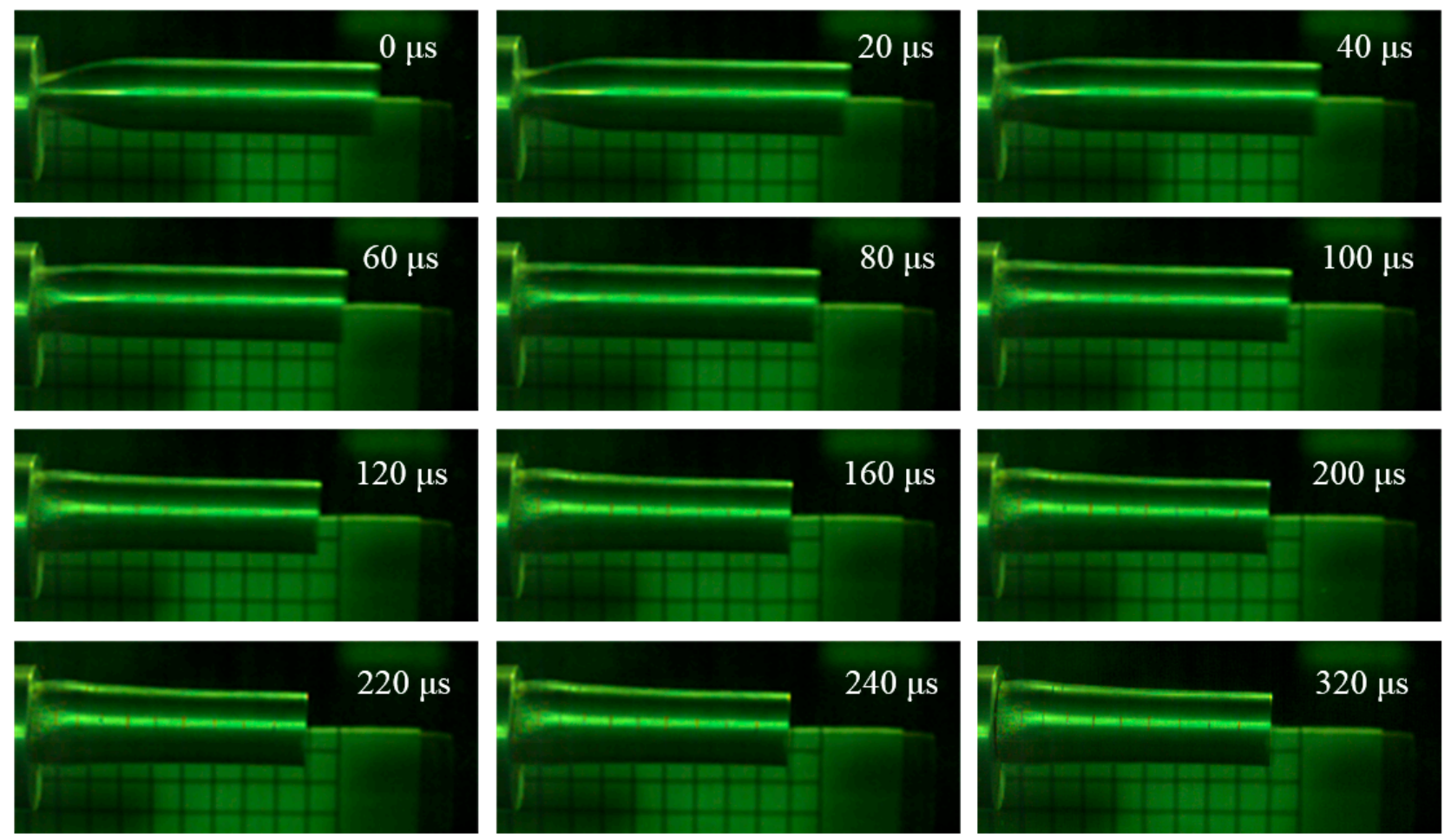

Figure 9. Series of high-speed photographs of the Taylor impact of the truncated ogive projectile $(165 \mathrm{~m} / \mathrm{s})$. 

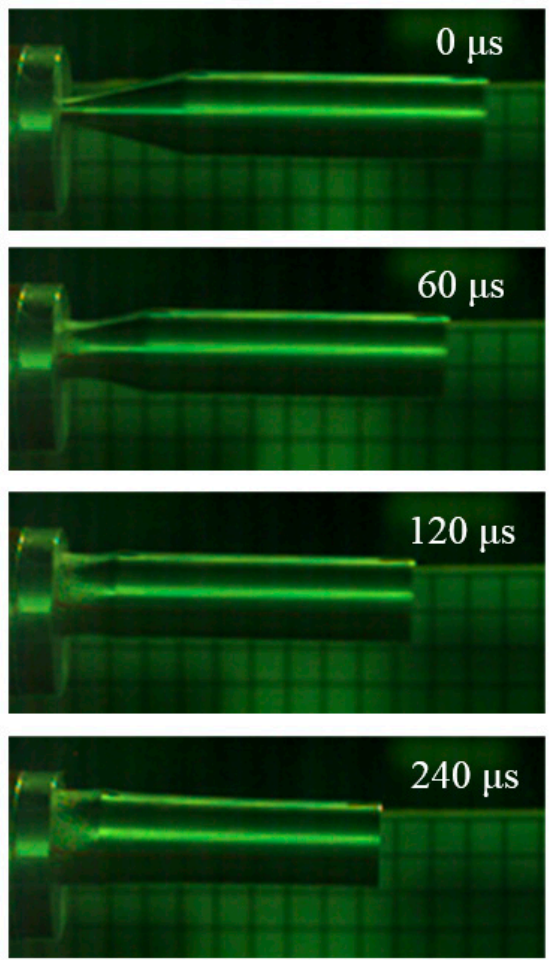
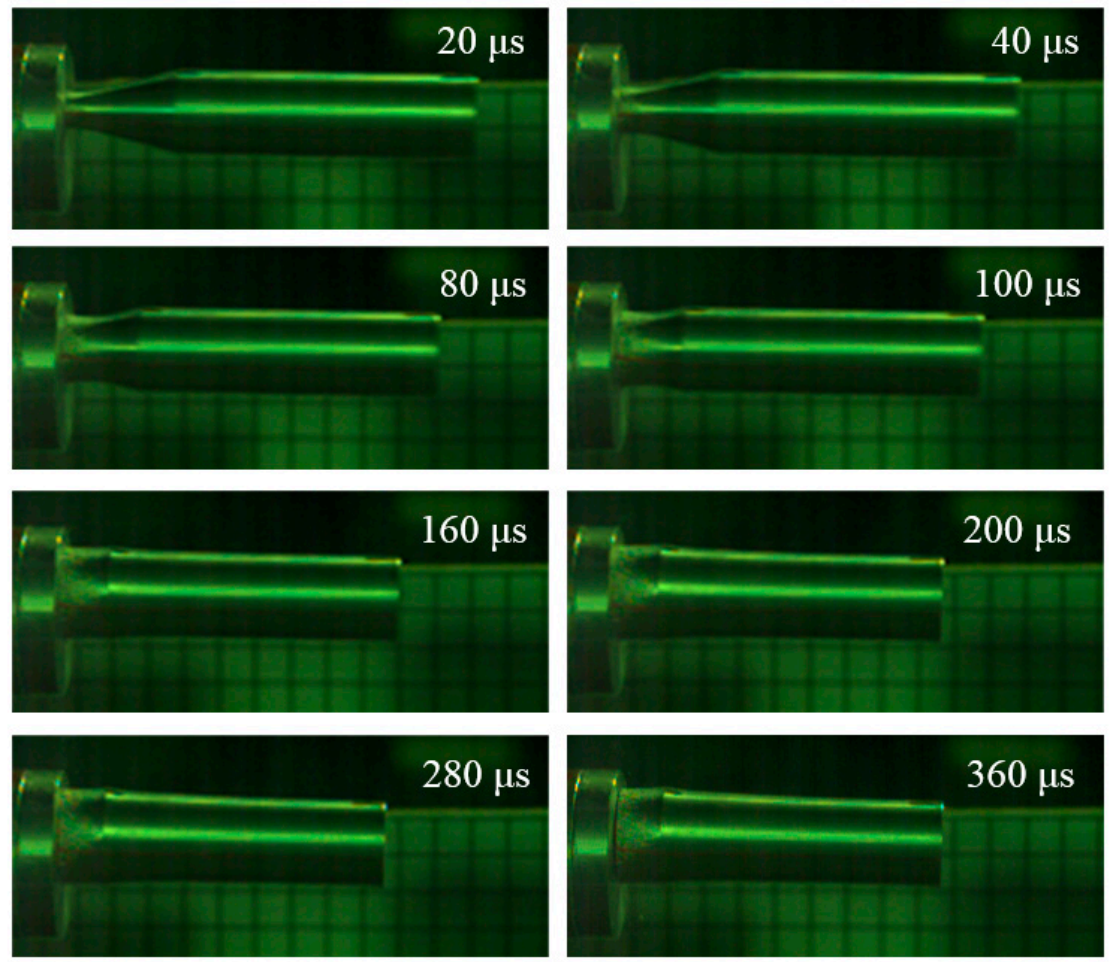

Figure 10. Series of high-speed photographs of the Taylor impact of the truncated conical projectable $(168 \mathrm{~m} / \mathrm{s})$.

The contour contrast of the recovered projectiles under different impact velocities is shown in Figure 11. A similarity is observed between the deformation modes of the blunt and hemispherical projectiles. After impact, the blunt and hemispherical test piece noses exhibit upsetting in the typical mushroom formation, where high impact velocities induce increased nose upsetting. For the truncated ogive and conical projectiles, at velocities less than $165 \mathrm{~m} / \mathrm{s}$, the diameter after the top pier is smaller than the projectile diameter. Furthermore, at velocities greater than $165 \mathrm{~m} / \mathrm{s}$, a mushroom head similar to that of the blunt projectile is formed on top of the projectile, and the nose edge is slightly cracked. The deformation of the truncated ogive and conical projectiles is concentrated on the projectile nose owing to its pointed arch, and the local deformation of the projectiles with these two nose shapes is greater than that of the blunt projectile. Figure 11 shows that surface folds form via the large deformation of the materials on the impact end side of the truncated ogive and conical projectiles.

A point selection test was carried out on the recovered projectiles along the axial direction to obtain the external projectile dimensions after deformation. The data were plotted together with the original design dimensions of the projectile, and the comparison of the projectile external dimensions before and after impact is presented in Figure 12. The tail ends of all projectile types were basically in the undisturbed state and, approaching the impact end, the projectile gradually expanded into a mushroom shape. The deformation comprising a thick nose pier and that comprising a thick nose pier with edge cracking occur successively for the same projectile nose type as the impact velocity increased. In terms of length compression, the truncated ogive and conical projectiles exhibited significantly higher compression than the blunt and hemispherical projectiles. 


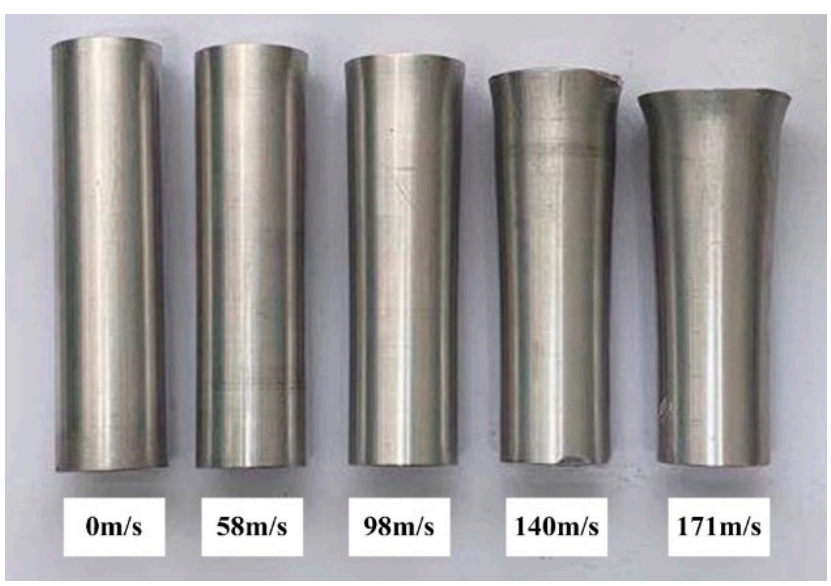

(a) Blunt

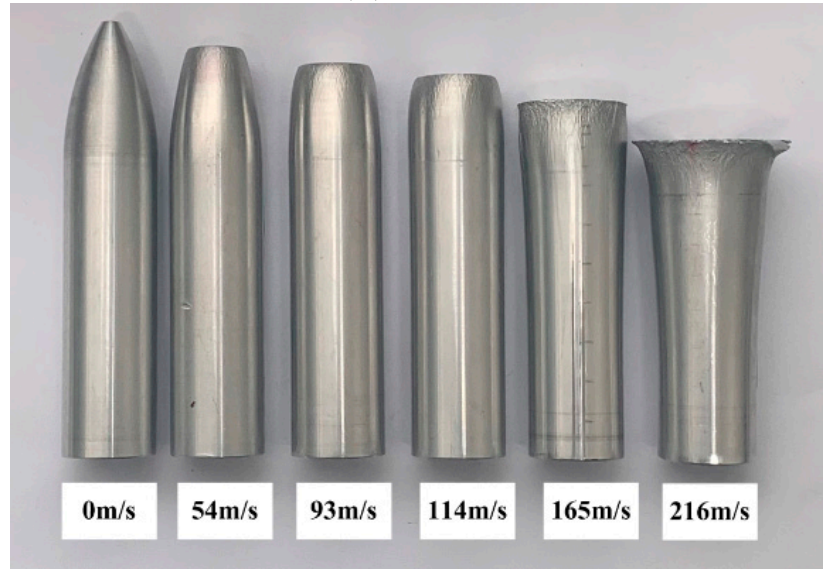

(c)Truncated ogive

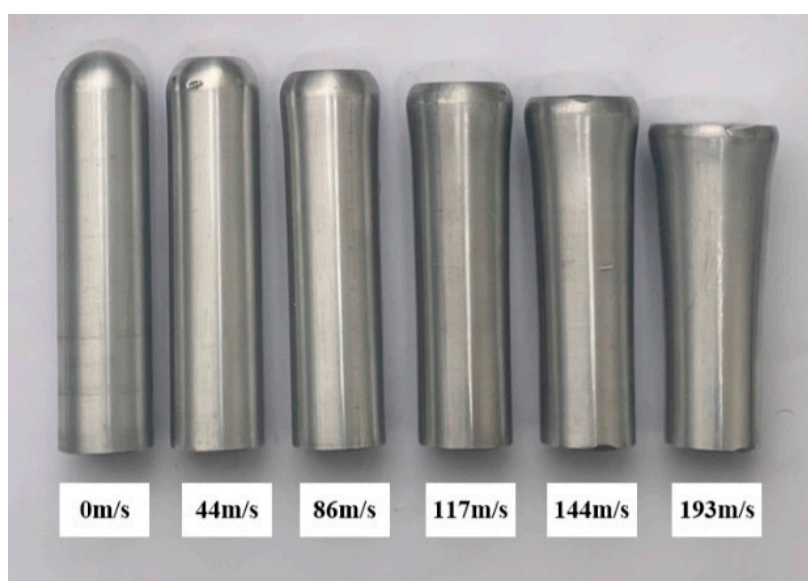

(b)Hemisperical

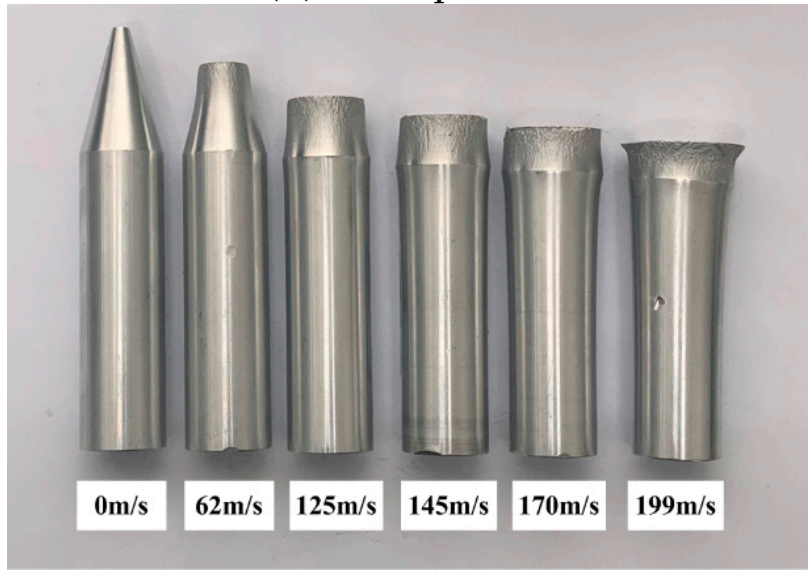

(d)Truncated conical

Figure 11. Contour contrast of recovered projectiles under different impact velocities.

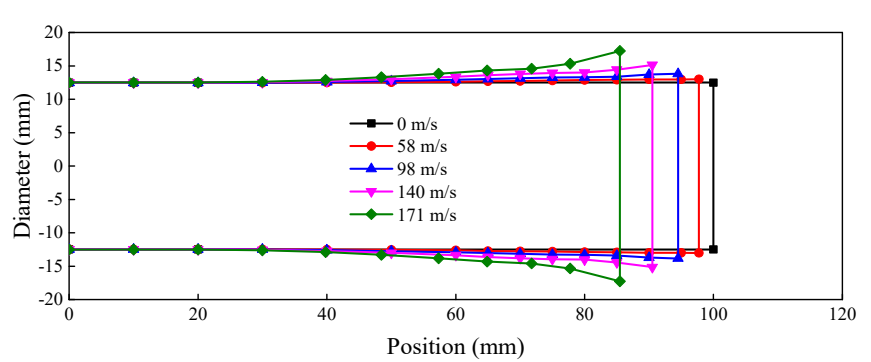

(a) Blunt

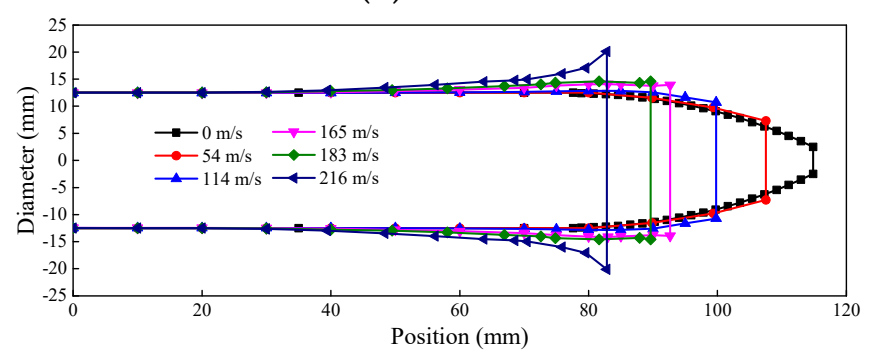

(c)Truncated ogive

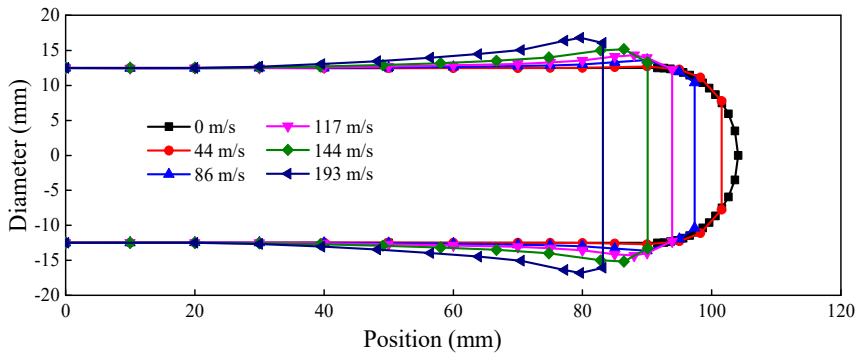

(b) Hemisherical

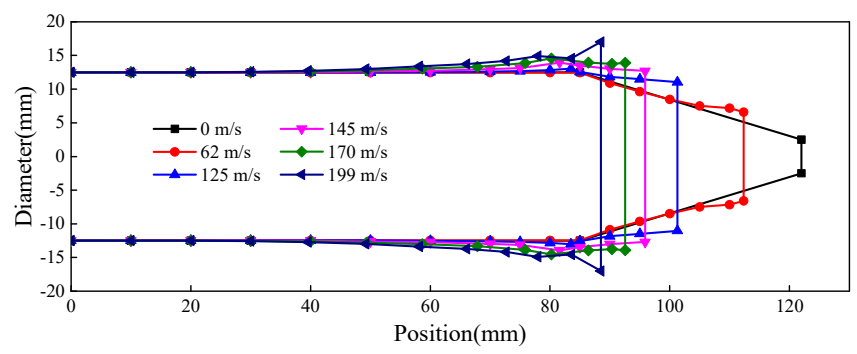

(d) Truncated conical

Figure 12. Comparison of initial dimensions and final deformation of the four types of projectiles. 
Statistical comparisons were made of the changes in the projectile length and top diameter after impact, and the relationship of these two measurements as a function of different factors is shown in Figure 13. The ordinate in the figure is the dimensionless residual length (the ratio of the residual length of projectile to the initial length). The changes reflect the anti-deformation ability of different nose-shape projectiles. The residual projectile length decreases and the top diameter increases with the increasing impact velocity. Under the same velocity, the length change of the blunt projectile is the least, followed by the hemispherical projectile, while that of the truncated conical projectile is the greatest. Examining the change in the top diameter, the relative changes of the truncated ogive and truncated conical projectiles are significantly greater than those of the blunt and hemispherical projectiles, reflecting the strong anti-deformation ability of the blunt and hemispherical projectiles and the significant nose shape change characteristics of the truncated ogive and conical projectiles.

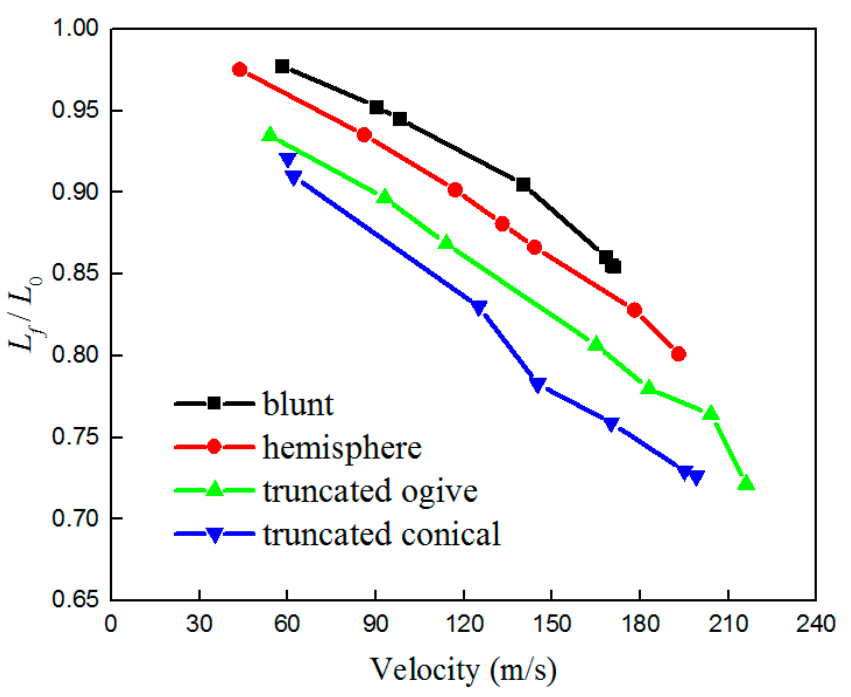

(a) Residual length vs. impact velocity

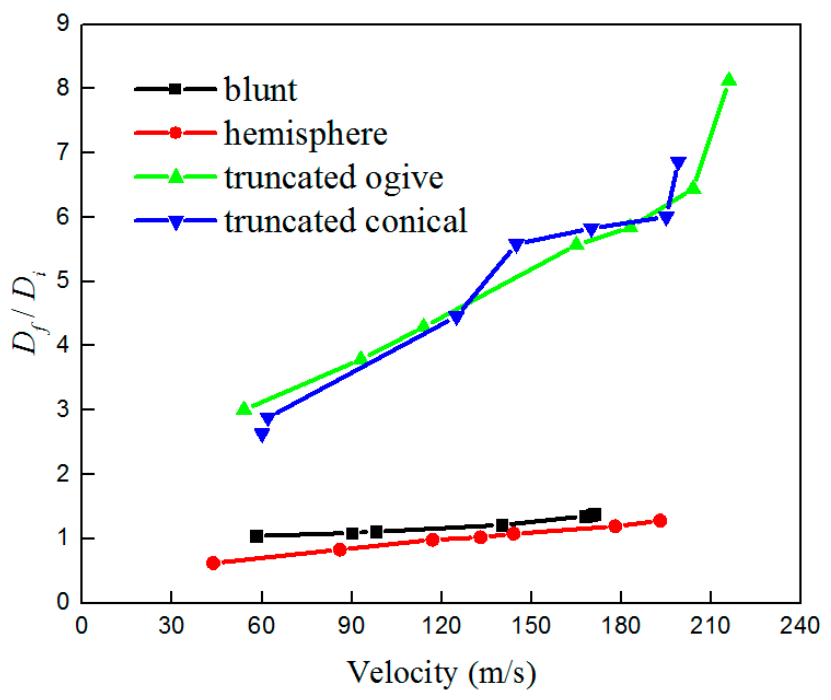

(b) Top diameter vs. impact velocity

Figure 13. Comparison of external contour changes.

Figure 14 (blunt projectile with $171 \mathrm{~m} / \mathrm{s}$ impact velocity) includes the incident pulse signal generated by the impact and the reflected pulse signal formed after reflection at the free end of the incident bar. No superposition of the two signals occurred, indicating that the incident pulse signal can completely manifest the impact force change during the impact process. The strain is converted into the impact force at the impact end using the following equation.

$$
F(t)=\sigma(t) \cdot S_{b a r}=E_{b a r} \cdot \varepsilon(t) \cdot S_{b a r}
$$

where $S_{b a r}$ is the cross-sectional area of the incident bar, $E_{b a r}$ is the elastic modulus of the incident bar, and $\varepsilon(t)$ is the measured strain of the incident bar.

Equation (1) was used to process the incident pulse signal data to get the impact force, which was then divided by the mass of the projectile to get the acceleration, as shown in Figure 15. The maximum value in the curve was selected as the peak acceleration, the projectile experienced an impact environment with a peak value of about $16.8 \times 10^{4} \mathrm{~g}$ (where $1 \mathrm{~g}=9.8 \mathrm{~m} / \mathrm{s}^{2}$ ) and a loading duration of about $177 \mu \mathrm{s}$. Integrating the projectile acceleration curve yields the velocity variation curve, as shown in Figure 16, giving a $-174 \mathrm{~m} / \mathrm{s}$ velocity variation over the entire impact process, which is equivalent to the initial velocity $(171 \mathrm{~m} / \mathrm{s})$. The integral result is slightly higher than the initial velocity because of the small rebound velocity $(-3 \mathrm{~m} / \mathrm{s})$ after the impact, which is consistent with the test observation. Thus, it is demonstrated that the strain test signal can correctly reflect the projectile deceleration process. 


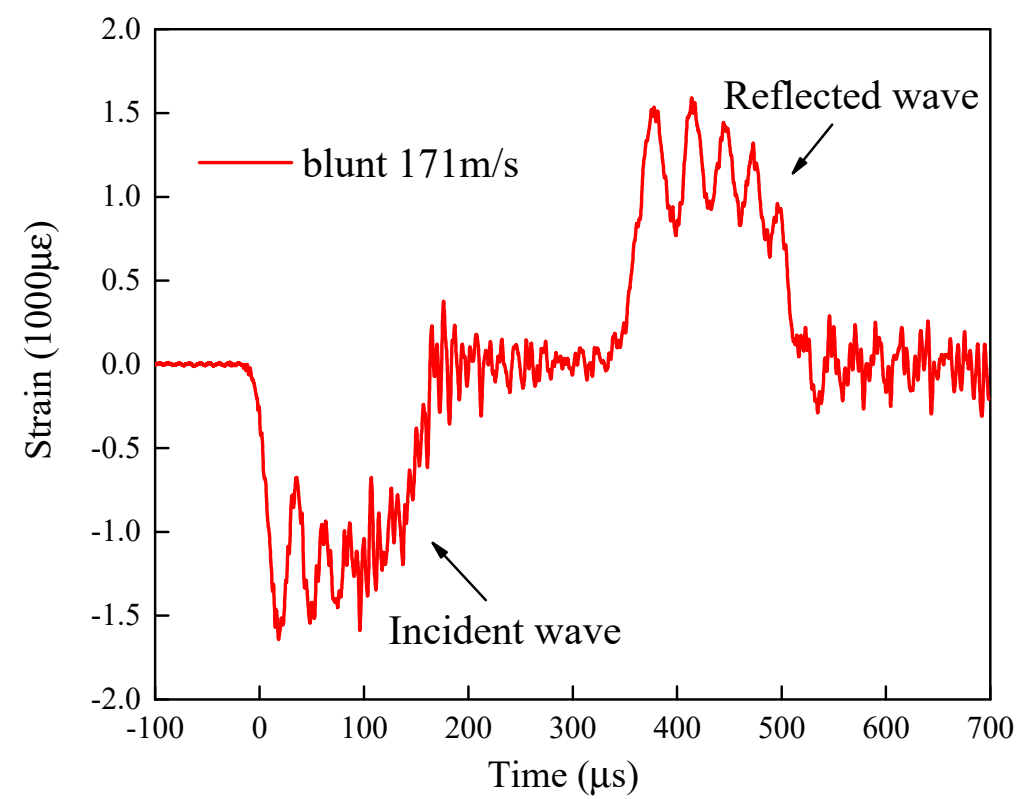

Figure 14. Strain-time signal measured on the Hopkinson bar (blunt projectile with $171 \mathrm{~m} / \mathrm{s}$ impact velocity).

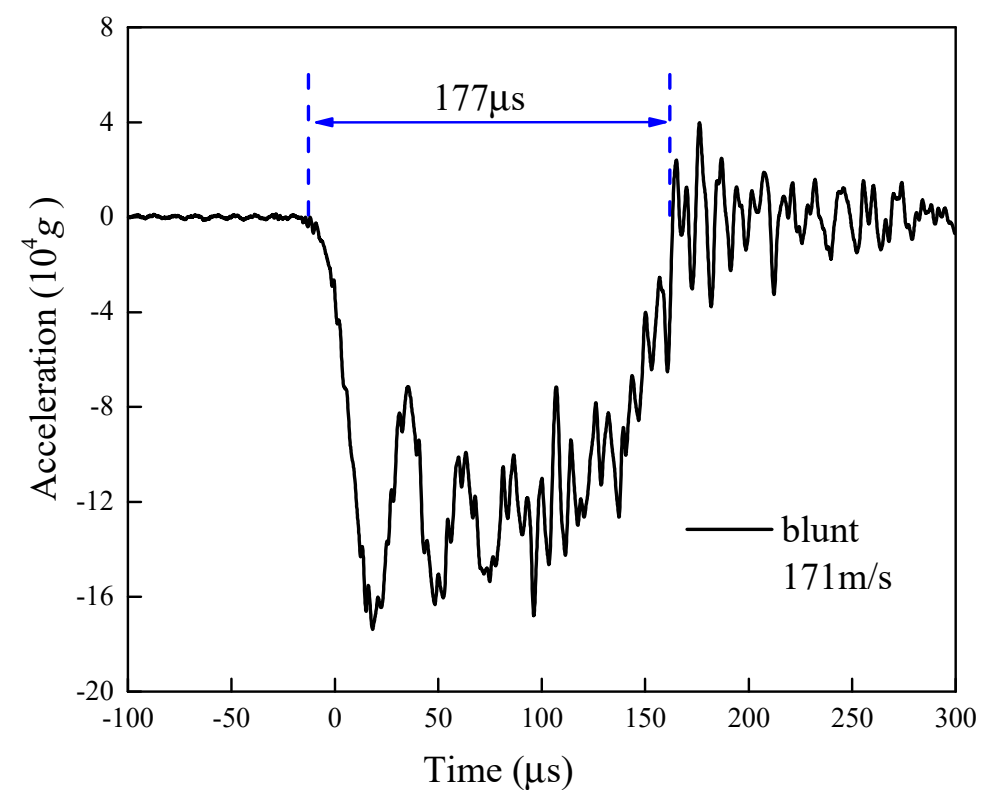

Figure 15. Acceleration curve of the blunt projectile (171 m/s initial velocity).

Using the same data processing method, the peak impact force, the duration of loading, and the peak acceleration value of each launch test were obtained, as shown in Table 3. The different nose-shape projectiles under various impact velocities underwent a high $g$ loading process with an amplitude of (3-20) $\times 10^{4} \mathrm{~g}$ and a period of $100-300 \mu \mathrm{s}$.

A comparison of the load curves obtained at different impact velocities for each of the nose-shape projectiles is shown in Figure 17. These curves show that a particular nose shape at different velocities produces load waveforms that have similar characteristics. In particular, the impact load of the blunt projectile (Figure 17a) has the same rising rate at different velocities and an essentially consistent maximum load time, while the maximum impact force and the load duration increase with impact velocity. The load curve of the hemispherical projectile (Figure 17b) is similar to that of the blunt projectile, with an approximately trapezoidal curve waveform. The rising edge of the load curve of the truncated ogive projectile (Figure 17c) increases with the impact velocity, and though 
the load duration does not change with impact velocity, the waveform is approximately half-sinusoidal. The load curve of the truncated conical projectile (Figure 17d) is similar to that of the truncated ogive projectile, whose waveform is approximately a triangular wave.

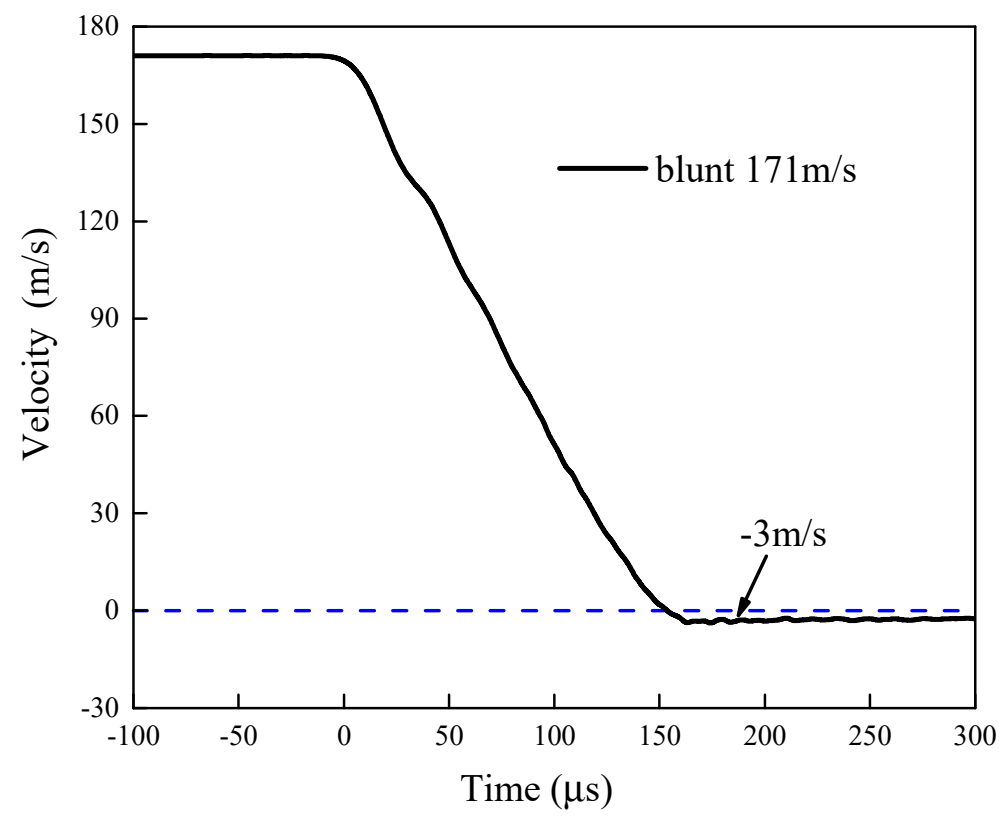

Figure 16. Velocity curve of the blunt projectile $(171 \mathrm{~m} / \mathrm{s}$ initial velocity) obtained by integrating the acceleration curve (Figure 15).

Figure 18 shows a comparison of the impact load curves of the different projectiles at similar impact velocities $(165-178 \mathrm{~m} / \mathrm{s})$. The overall variation trend indicates that the blunt and hemispherical projectiles have similar characteristics, including the impact force rapidly reaching the peak value in the initial stage of impact, a short impact process, and large oscillations along the length of the curve. In contrast, the load curves of the truncated ogive and conical projectiles exhibit a slow rising edge in the initial impact stage and a greater duration of loading than those of the blunt and hemispherical projectiles. The maximum load time of the truncated conical projectile lags that of the truncated ogive projectile, while the former exhibits a longer pulse width and slightly reduced maximum load compared to the latter. Moreover, the truncated ogive and conical projectiles exhibit a small overall impact load curve oscillation and a smooth waveform.

The impact load curves were analyzed to obtain the maximum load value (Figure 19) and load duration (Figure 20) for each nose-shape projectile, which were plotted as a function of impact velocity. At the same velocity, the blunt projectile produced the highest peak load and the smallest pulse width. The truncated conical projectile impact produced the lowest peak load and the greatest pulse width. The results in Figure 19 show that the peak value of the load produced by the impact of a particular nose shape significantly increased with impact velocity. However, the results in Figure 20 for the pulse width reveal that the performance is slightly different for each nose shape. The variation trends of the blunt and hemispherical projectiles are similar; that is, the pulse width increased with impact velocity. However, the pulse width of the truncated ogive projectile under different impact velocities fluctuated in a small range. The variation curve is approximately linear, indicating that a significant velocity increase does not induce an obvious variation in pulse width. Therefore, the load duration of the projectile with a truncated ogive nose shape is insensitive to the impact velocity. Finally, the pulse width of the truncated conical projectile decreased with the impact velocity, but the overall variation range is small. 


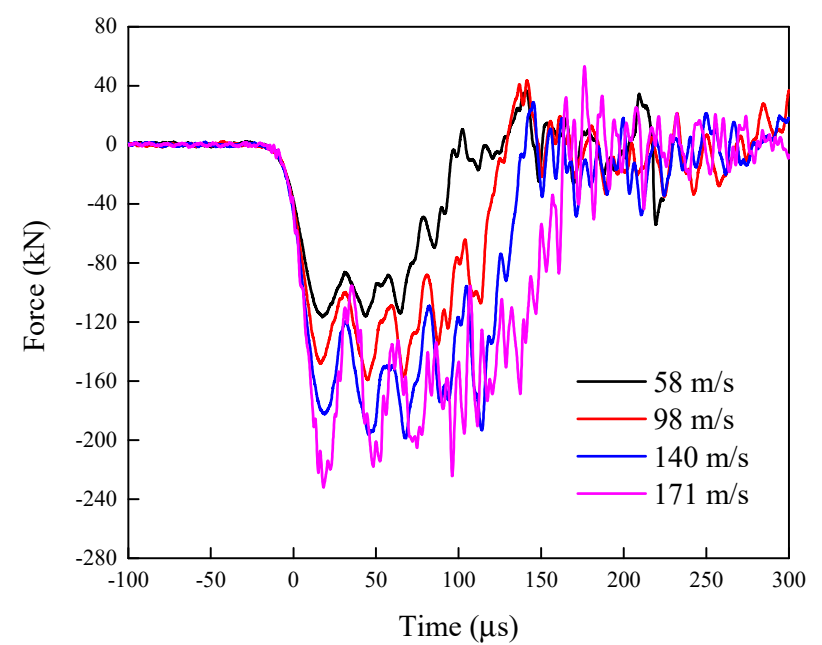

(a) Blunt

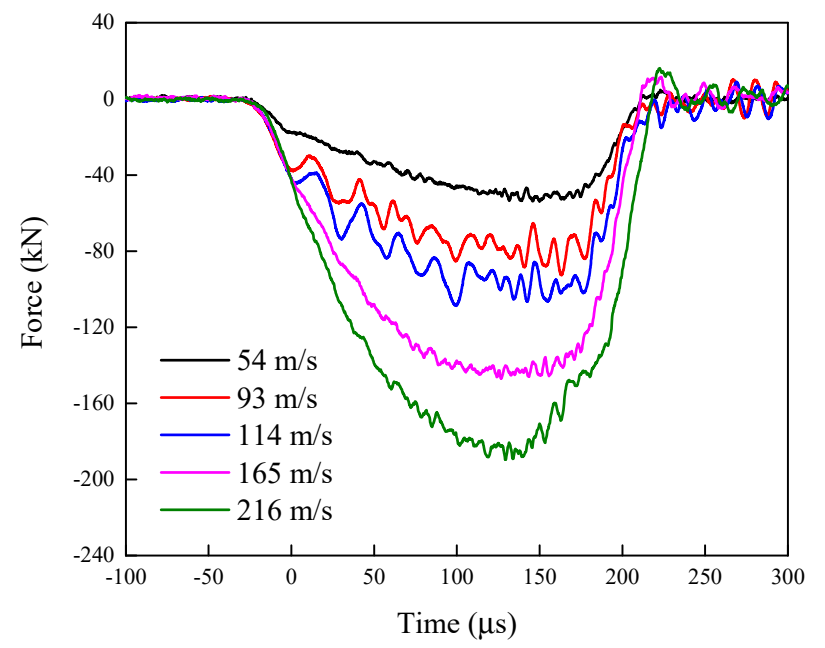

(c) Truncated ogive

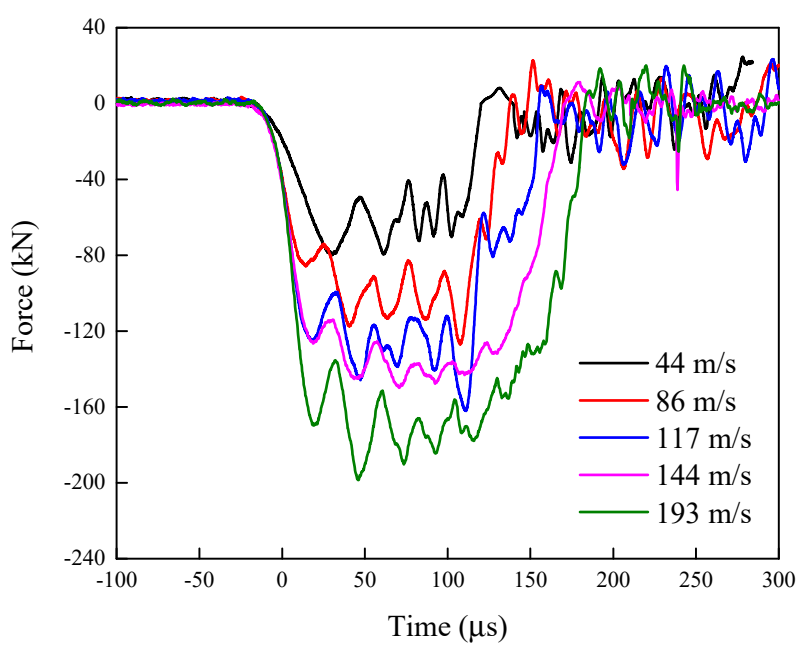

(b) Hemispherical

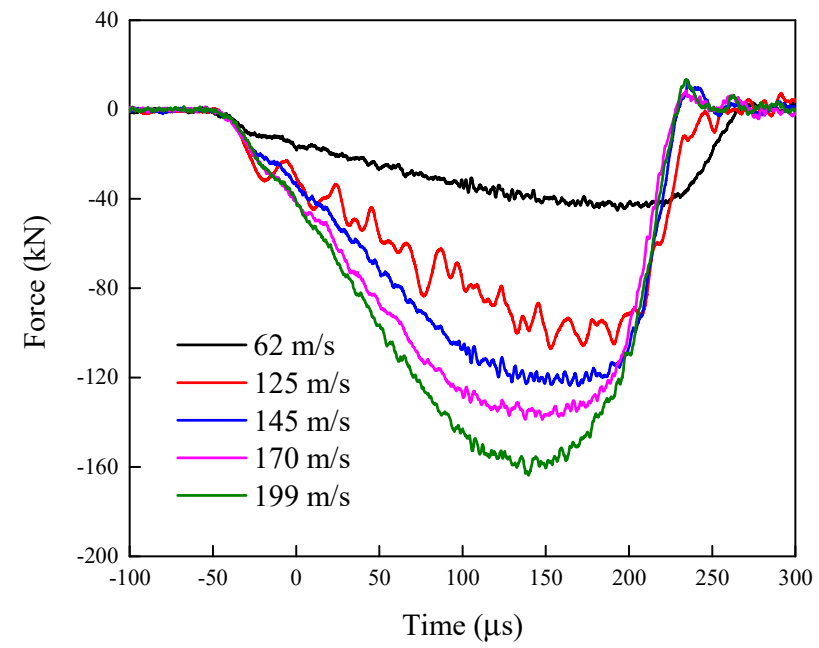

(d) Truncated conical

Figure 17. Impact load curve for varying impact velocities for the projectiles.

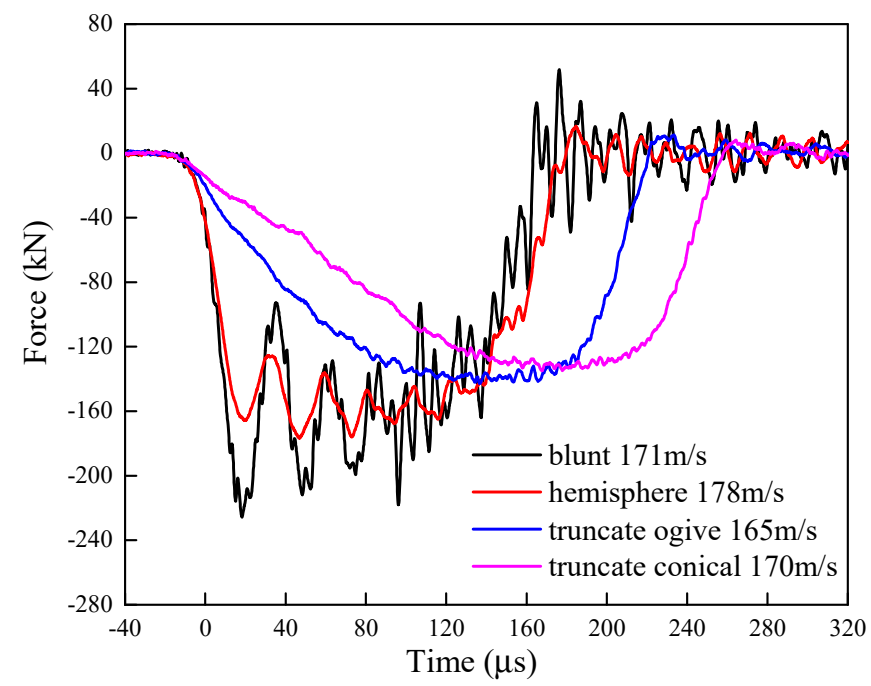

Figure 18. Impact load curve comparison for the different nose-shape projectiles at similar impact velocities. 


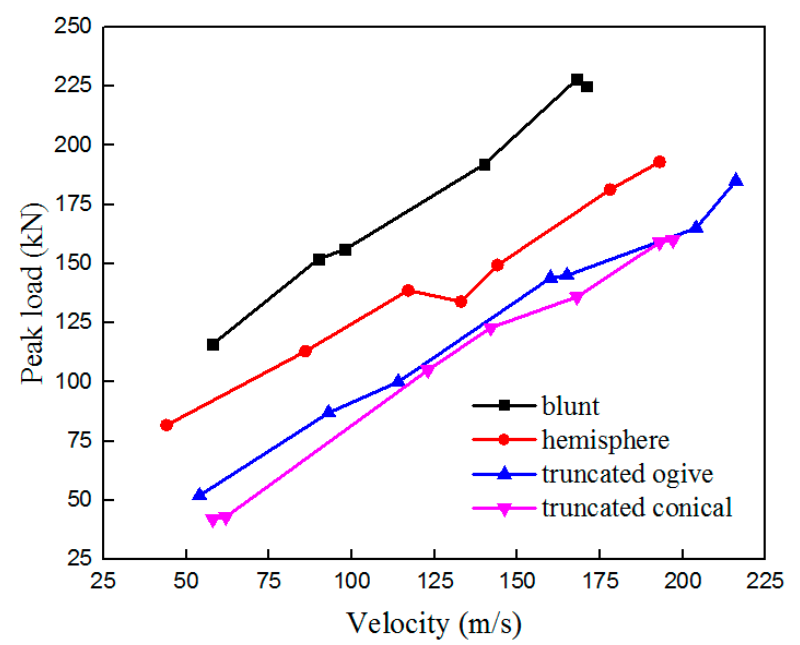

Figure 19. Peak load of various nose-shape projectiles vs. impact velocity.

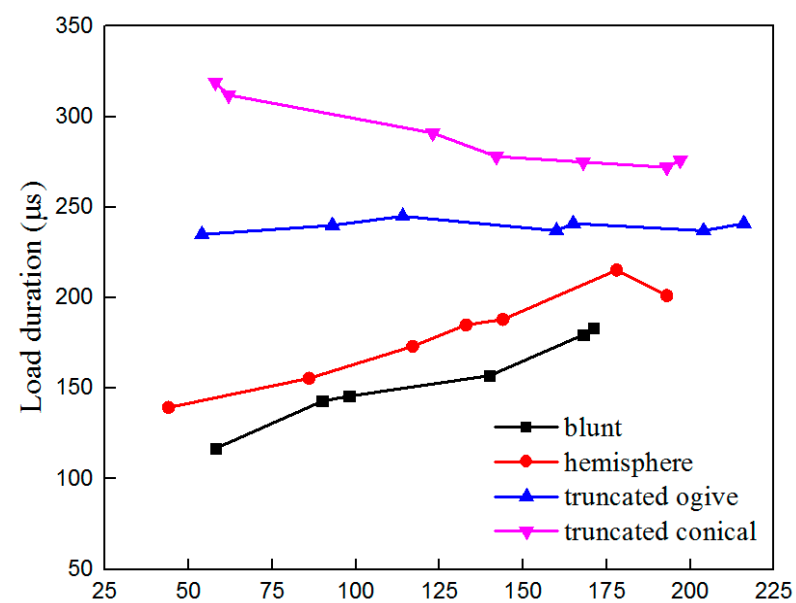

Figure 20. Pulse width of various nose-shape projectiles vs. impact velocity.

\subsection{Cause Analysis of Varying Impact Load Pulse Shapes}

According to the classical Taylor impact theory, the discontinuous stage motion process of a stress wave propagating back and forth in the projectile with gradually decreasing projectile velocity can be approximated as a continuous motion process. The impact motion model of the blunt projectile is shown in Figure 21, where $h(t)$ is the distance between the elastic-plastic interface and the rigid target surface; $x(t)$ is the length of the elastic region that has not been compressed into the plastic region; $u(t)$ is the elastic-plastic interface that moves to the left; and $v(t)$ is the forward velocity of the stress-free region.

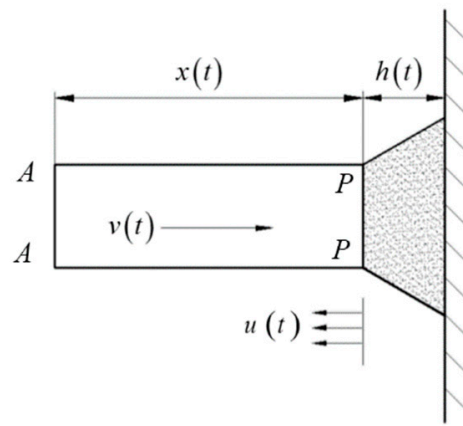

Figure 21. Taylor impact analysis diagram of the blunt projectile. 
If the initial length of the projectile is $L_{0}$, the initial velocity is $v_{0}$, the density of the projectile material is $\rho_{p}$, the elastic wave velocity is $C_{P}$, the dynamic yield strength of the projectile material is $\sigma_{Y C}^{D}$, and the required time for the impact-generated elastic wave to travel back and forth in the elastic region (i.e., between $\mathrm{A}$ and $\mathrm{P}$ ) is $\Delta t$, then we can obtain the following relation:

$$
\Delta t=\frac{2 x}{C_{p}} .
$$

According to the motion relationship within this duration,

$$
\begin{gathered}
\Delta h=u \Delta t \\
\Delta x=-(v+u) \Delta t \\
\Delta v=-\frac{2 \sigma_{Y C}^{D}}{\rho_{p} C_{p}}
\end{gathered}
$$

where $\Delta x$ is the change in length of the uncompressed elastic region in the time $\Delta t, \Delta h$ is the change in distance between the elastic-plastic interface and the rigid target surface in the time $\Delta t$, and $\Delta v$ is the velocity reduction in the time $\Delta v$ caused by the propagation of the stress wave in the elastic region and the reflection at the free end of the projectile tail. The time interval $\Delta t$ is considered to be very small, so a single round-trip propagation process can be considered equivalent to a continuous process within the limit. According to the derivative definition, we obtain the following equations:

$$
\begin{gathered}
\frac{d h}{d t}=u \\
\frac{d x}{d t}=-(v+u) \\
\frac{d v}{d t}=-\frac{\sigma_{Y C}^{D}}{x \rho_{p}} .
\end{gathered}
$$

Assuming that the material is incompressible, a region of the elastic material with section area $A_{0}$ and length $(u+v) d t$ is pressed into the plastic region within unit time interval $d t$. This section becomes material in the plastic region with section area $A$ and length $u d t$, although the volume remains unchanged. Thus, we obtain the continuity equation:

$$
A_{0}(u+v)=A u
$$

Considering the momentum conservation in unit time $d t$, the following equation can be obtained according to the momentum conservation equation [23]:

$$
\rho_{p} A_{0} v(u+v)=2\left(A-A_{0}\right) \sigma_{Y C}^{D} / 3
$$

Equations (6)-(10) constitute the equations of the Taylor impact theory for the blunt projectile. These five equations contain five variables, and the numerical integration method is used to solve these equations. The elastic wave velocity $C_{P}$ can be calculated from the density and elastic modulus of the material, which is $5091.8 \mathrm{~m} / \mathrm{s}$. According to the stress-strain curve in Figure 4, the dynamic yield strength $\sigma_{Y C}^{D}$ of the material is $226 \mathrm{Mpa}$. The initial conditions are as follows: $t=0, v=v_{0}, x=L_{0}, h=0, A=A_{1}$; and the final conditions are as follows: $t=t_{2}, v=0, x=L_{2}, h=h_{2}, A=A_{0}, u=0$. Here, $t_{2}$ is the end time of impact, $L_{2}$ is the length of the elastic region after impact, and $h_{2}$ is the length of the plastic region after impact. The residual length of projectile $L f$ is obtained by adding the length of elastic region $L_{2}$ and the length of plastic region $h_{2}$ after impact.

As the nose shape of the projectile changes and the impact area becomes a variable body cross-section, the elastic wave $\sigma_{i}$ generated by the impact can produce the reflected wave $\sigma_{r}$ and the transmitted wave $\sigma_{t}$ as the section changes. Assuming that the elastic 
wave propagates from section $S_{1}$ to section $S_{2}$, according to the total force on both sides of $S_{1}$ and $S_{2}$ and the same particle velocity, we can obtain the relationship

$$
\sigma_{t}=\frac{2 S_{1} \sigma_{i}}{S_{1}+S_{2}}
$$

For a stress wave that propagates from a section with radius $r$ to a section with radius $r+\Delta r$ at a specific moment, for a sufficiently small $\Delta r$, the relationship between the transmitted and the incident waves can be given as

$$
\sigma_{t}=\frac{2 \pi r^{2} \sigma_{i}}{\pi r^{2}+\pi(r+\Delta r)^{2}} .
$$

Omitting the higher-order $\Delta r^{2}$ term and simplifying Equation (12) yields the relationship

$$
\sigma_{t}=\frac{r \sigma_{i}}{r+\Delta r}
$$

According to Equation (13), the stress amplitude will decrease with increasing cross-section radius in the propagation of the elastic wave for a continuous variable circular cross-section.

Using the truncated conical projectile as an example, the Taylor impact analysis diagram is shown in Figure 22, where the nose cone angle is $2 \theta$, the nose radius is $R_{1}$, the radius of the cylindrical segment is $R_{2}$, the initial projectile length is $L_{0}$, and the initial impact velocity is $v_{0}$.

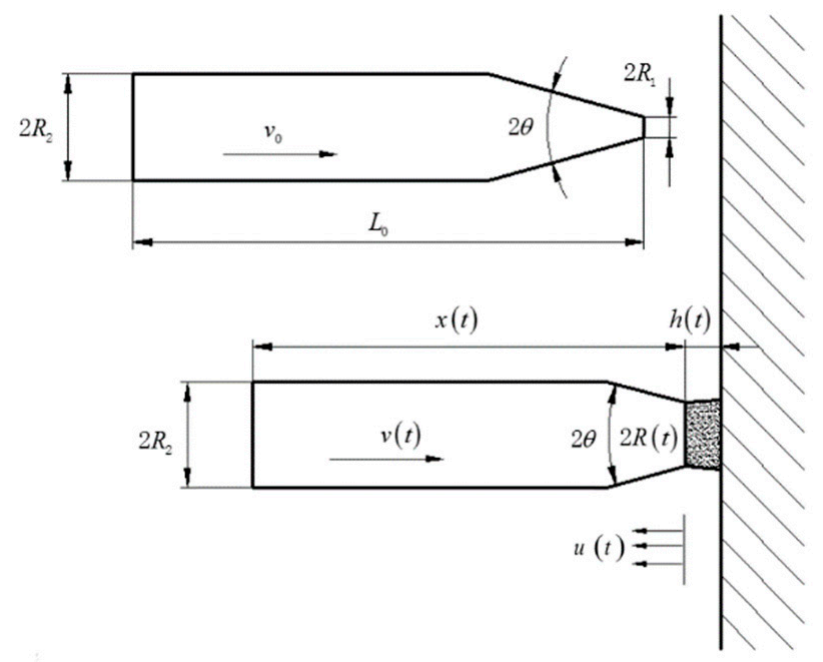

Figure 22. Taylor impact analysis of the truncated conical projectile.

Unlike the blunt projectile, during the propagation of the truncated conical projectile, the elastic compression wave generated by the nose impact will change the stress wave amplitude at different sections before ultimately reaching the cylindrical section of the projectile. As the stress wave reaches the projectile cylindrical section, the amplitude of the stress wave decreases from $\sigma_{Y C}^{D}$ to $\left(\sigma_{t}\right)_{x}$, where $x=L_{0}-\left(R_{2}-R_{1}\right) / \tan \theta$. According to Equations (5) and (13), the particle velocity of the truncated conical projectile variation is

$$
\Delta v=-\frac{2\left(\sigma_{t}\right)_{x}}{\rho_{p} C_{p}}=-\frac{4 \sigma_{Y C}^{D}\left[R_{1}+\left(L_{0}-x\right) \tan \theta\right]^{2}}{\rho_{p} C_{p}\left\{\left[R_{1}+\left(L_{0}-x\right) \tan \theta\right]^{2}+R_{2}^{2}\right\}}\left(\left(L_{0}-x\right) \tan \theta \leq R_{2}-R_{1}\right)
$$

which is caused by the stress wave propagation within the projectile and the reflection at the free end of the projectile tail. As the plastic deformation region reaches the projectile cylindrical segment, the elastic wave propagates back and forth once. The expression of 
particle velocity variation in the elastic region is the same as that of the blunt projectile, given as:

$$
\Delta v=-\frac{2 \sigma_{Y C}^{D}}{\rho_{p} C_{p}}\left(\left(L_{0}-x\right) \tan \theta>R_{2}-R_{1}\right) .
$$

According to Equations (6), (7), (9), and (10) the Taylor impact of the truncated conical projectile can be predicted via the numerical integration method using the same starting and ending conditions as the blunt projectile. Similarly, the Taylor impact analysis model of the hemispherical and truncated ogive projectiles can be obtained using a similar derivation process.

Figure 23 shows the theoretical predictions and the actual test data for the residual length of the projectile for varying impact velocities. The ordinate in the figure is the dimensionless residual length (the ratio of the residual length of projectile $L_{f}$ to the initial length $L_{0}$ ). A good consistency can be seen between the calculated and actual results, with an error of less $5 \%$, indicating that the theoretical analysis model can adequately predict the actual results. For the same impact velocity, the theoretical residual lengths of the blunt and hemispherical projectiles are larger than those of the truncated ogive and truncated conical projectiles, indicating that the blunt and hemispherical projectiles have a strong anti-deformation ability, which is consistent with the test results.

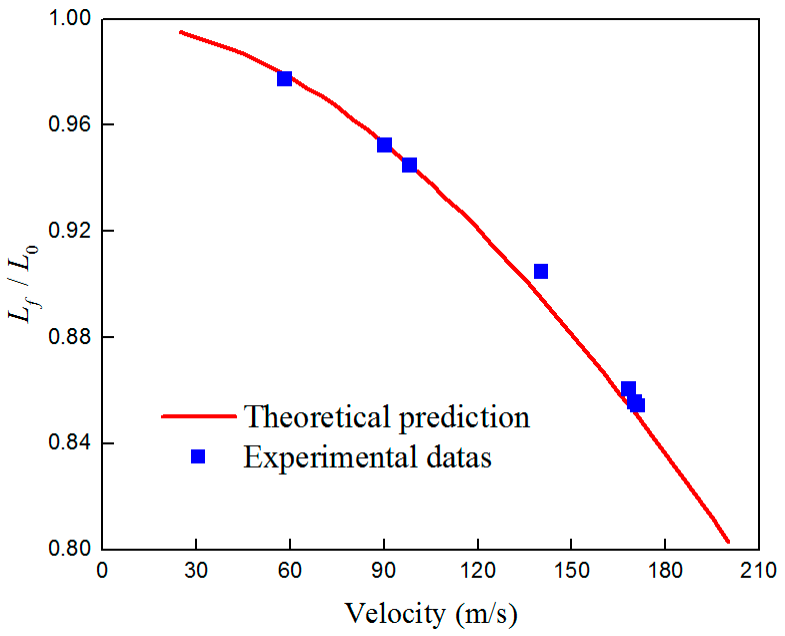

(a) Blunt

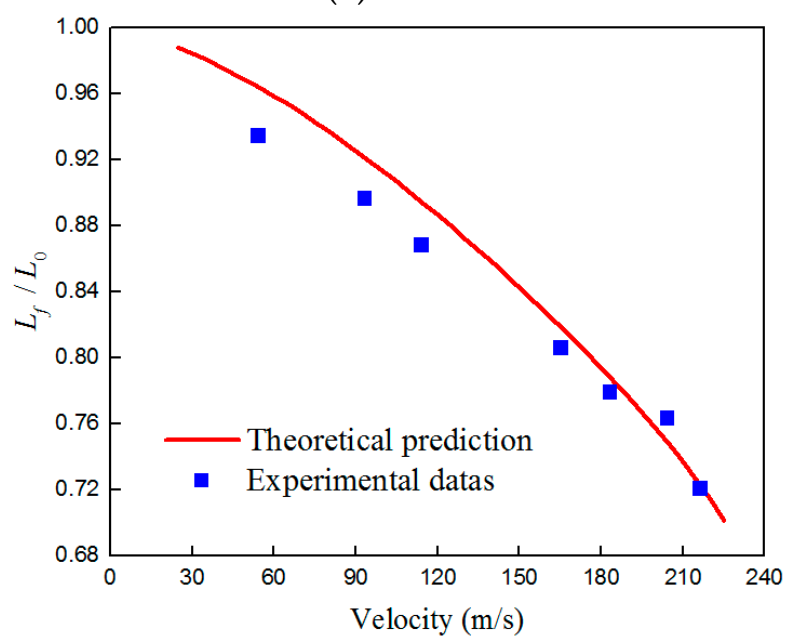

(c) Truncated ogive

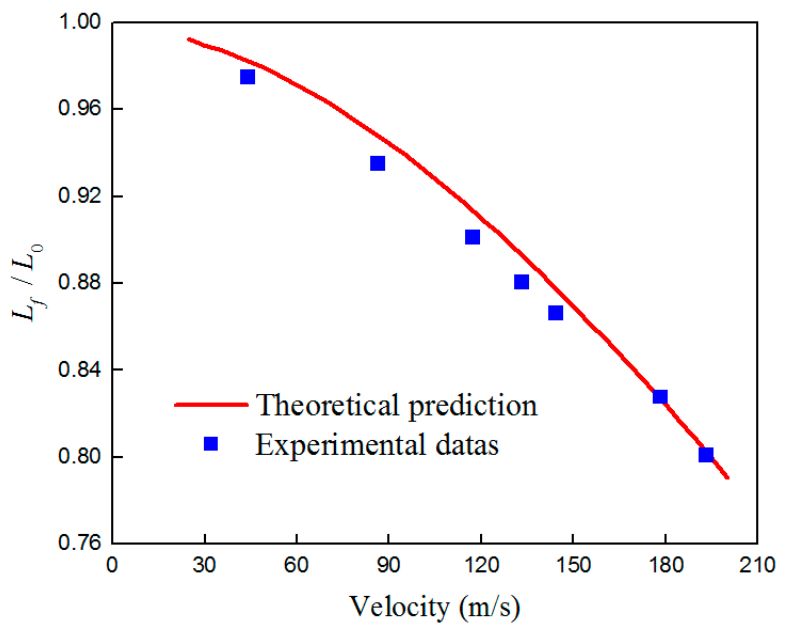

(b) Hemispherical

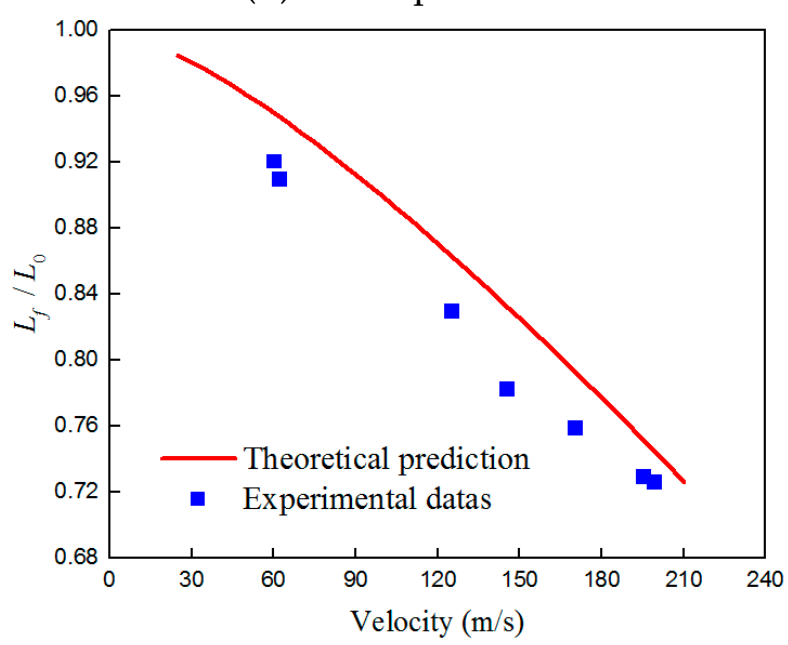

(d) Truncated conical

Figure 23. Comparison of theoretical prediction (red line) and test data (blue squares) for the residual length of the projectiles. 
The velocity and acceleration of the elastic deformation area are used to approximately characterize the velocity and acceleration of the entire projectile. Thus, the time history curves of the different nose-shape projectiles under the same impact velocity are compared in Figure 24. Considering velocity variation, the velocity of the blunt projectile decreased the fastest (i.e., least time for the entire impact process), which was followed by the hemispherical and truncated conical projectiles. At the initial impact, the velocity variations of the truncated ogive and conical projectiles were relatively gentle with a small loss of velocity; thus, the entire duration of loading was prolonged compared to that of the blunt and hemispherical projectiles. Considering the acceleration change of the projectile body, the acceleration of the blunt projectile rapidly reached a higher level at the initial impact stage, exhibiting a steep rising edge on the curve. However, the accelerations of the hemispherical, truncated ogive, and truncated conical projectiles are relatively gentle. Meanwhile, the accelerations of the truncated ogive and conical projectiles are clearly less than those of the blunt and hemispherical projectiles, while the acceleration vs. time curve shapes of the truncated ogive and conical projectiles respectively exhibit an arc-shaped rising edge and conical rising edge, which are similar to the nose shape of the projectile.

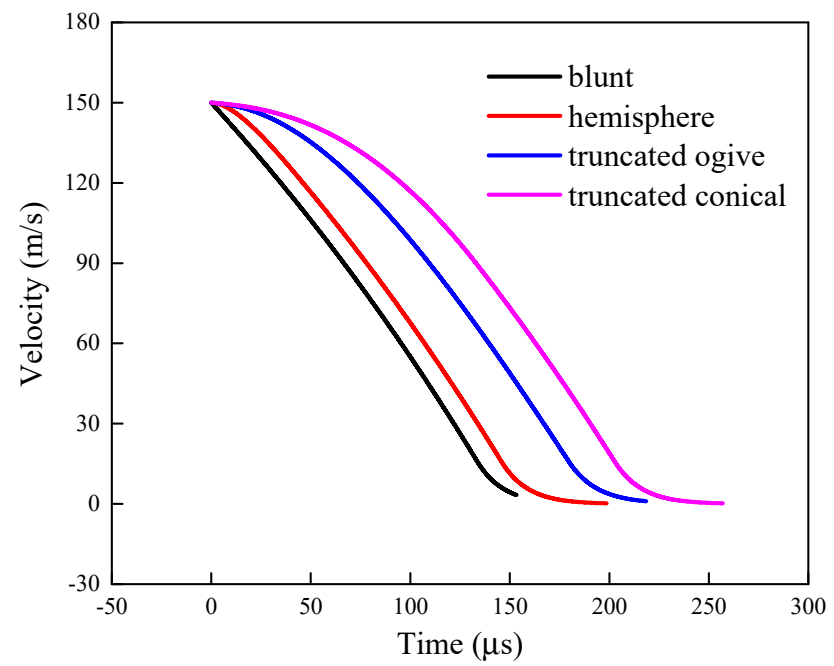

(a) Comparison of velocity curves

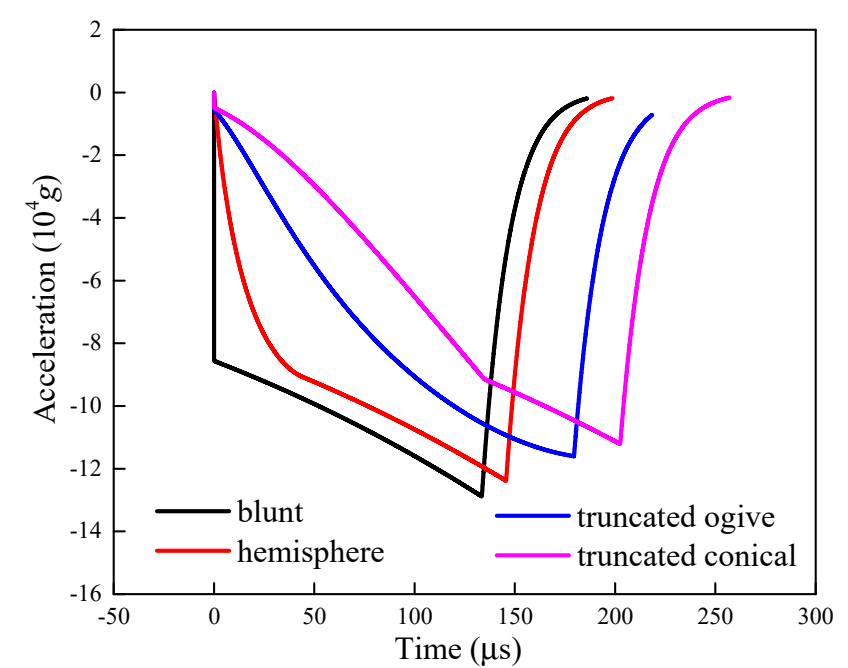

(b) Comparison of acceleration curves

Figure 24. Time history curve comparison during the impact of the different nose-shape projectiles.

According to the Taylor impact theory, the velocity variation of the projectile is caused by back-and-forth propagation within the projectile of the elastic wave generated by the nose impact. As the nose shape changes, the propagation path of the elastic wave in the projectile body changes from the constant section propagation of the blunt projectile to the continuous variable section propagation of the other nose types. According to Equation (13), the stress amplitude decreases with increasing section radius during the propagation of the stress wave, which can reduce the particle velocity in the propagation region. This phenomenon is reflected in the acceleration curve of the projectile body in the form of a slow rising edge at the initial impact stage. Moreover, the variation law of the section radius is determined by the geometric parameters or the shape function of the projectile nose, allowing the particle velocity in the propagation region to slowly decrease. Meanwhile, the acceleration curve can exhibit a rising edge similar to the nose shape. Finally, the variation law of the nose section shape is reflected in the acceleration curve and can affect the entire waveform, which is also the primary reason for the different impact load pulse shapes produced by the different nose types. 


\section{Discussion}

One of the important characteristics of the Taylor impact test is that the sample nose undergoes a large plastic deformation, while the tail remains elastic. Thus, the Taylor impact sample can be divided into the two areas, namely, the plastic and elastic deformation areas. The impact load acting on the elastic deformation area is generated at and transferred by the plastic deformation area at the front end of the sample. Meanwhile, the plastic deformation area at the front end of sample can be regarded as the generator of the impact load, and the elastic deformation area at the back end can be considered as the impacted portion. According to the analysis herein, the shape of the sample nose is the primary influencing factor of the load waveform, while the impact velocity primarily affects the peak value of the load. In this paper, pulse loads with approximate trapezoidal, half-sinusoidal, and the triangular waveforms were obtained during the Taylor impact test of four typical nose-shape projectiles. Moreover, requirements for the impact environment characteristics can be controlled by the design of the projectile nose shape and the control of impact speed. Therefore, the loaded components (such as fuses, missile-borne recording devices, etc.) can be installed at the tail of the Taylor impact sample, as shown in Figure 25. According to the purpose of this test, an appropriate nose shape for the projectile can be designed and the impact velocity can be controlled to achieve the required high $g$ loading impact environment.

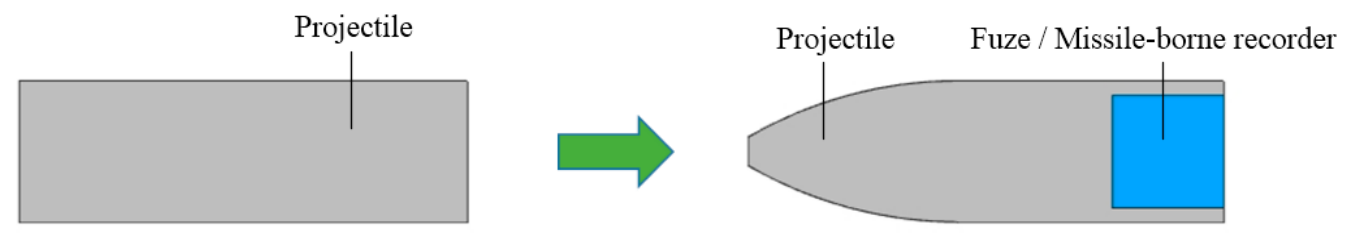

Figure 25. Sample structural design for a high $g$ loading test.

We note that the physical size of the testing samples in this paper were small, which we present as a principle verification test. In practical applications, it will be necessary to increase the sample size to accommodate the actual size of a loaded part, and an air gun with a larger caliber (such as $\varnothing 100 \mathrm{~mm}, \varnothing 120 \mathrm{~mm}$ ) must be selected as the test piece launching platform. Preliminary analysis shows that an overall high $g$ loading environment with a peak value of (3-5) $\times 10^{4} \mathrm{~g}$ and a period of about $1 \mathrm{~ms}$ can be achieved for a projectile with a mass of $\approx 5 \mathrm{~kg}$ and a diameter of $120 \mathrm{~mm}$.

\section{Conclusions}

(1) The nose shape of the projectile significantly changes the waveform, and the pulse duration of the impact load is the primary control factor for the load waveform.

(2) The impact velocity determines the impact energy and primarily affects the peak value of the impact load.

(3) According to the test load, the sample underwent a high $g$ loading process with an amplitude of $(3-20) \times 10^{4} \mathrm{~g}$ and a period of $100-300 \mu \mathrm{s}$.

(4) Pulse loads with approximate trapezoidal, half-sinusoidal, and the triangular waveforms were obtained, indicating that the Taylor impact test can generate shock loading with specific pulse shape. The result support the assumption that the Taylor impact test can be applied to the high $g$ loading test.

Author Contributions: Investigation, writing —original draft, J.-C.L.; funding acquisition, methodology, writing-review and editing, G.C.; supervision, Y.-G.L.; review and editing, F.-L.H. All authors have read and agreed to the published version of the manuscript.

Funding: This research was funded by the National Natural Science Foundation of China (grant number 11572299).

Institutional Review Board Statement: Not applicable. 
Informed Consent Statement: Not applicable.

Data Availability Statement: All relevant data are within the manuscript.

Acknowledgments: The authors would like to thank the National Natural Science Foundation of China (NO.: 11572299) for supporting the present work. The funders had no role in study design, data collection and analysis, decision to publish, or preparation of the manuscript. We also thank Sara Maccagnano-Zacher, for editing the English text of a draft of this manuscript.

Conflicts of Interest: The authors declare no conflict of interest.

Ethics Statement: N/A.

\section{References}

1. Taylor, G.I. The Use of Flat-Ended Projectiles for Determining Dynamic Yield Stress. I: Theoretical considerations. Proc. R. Soc. Lond. 1948, 194, 289-299.

2. Whiffin, A.C. The Use of Flat-Ended Projectiles for Determining Dynamic Yield Stress. II. Tests on Various Metallic Materials. Proc. R. Soc. Lond. 1948, 194, 300-322.

3. Testa, G.; Iannitti, G. Preliminary investigation on impact resistance of additive manufactured Ti-6Al-4V. Procedia Struct. Integr. 2018, 12, 589-593. [CrossRef]

4. Bloniarz, R.; Majta, J.; Trujillo, C.; Cerreta, E.; Muszka, K. The mechanisms for strengthening under dynamic loading for low carbon and microalloyed steel. Int. J. Impact Eng. 2018, 114, 53-62. [CrossRef]

5. Revil-Baudard, B.; Cazacu, O.; Flater, P.; Kleiser, G. Plastic deformation of high- purity $\alpha$-titanium: Model development and validation using the Taylor cylinder impact test. Mech. Mater. 2015, 80, 264-275. [CrossRef]

6. Chen, G.; Huang, X. Simulation of deformation and fracture characteristics of a 45 steel Taylor impact specimen. Eng. Trans. 2016, 64, 225-240.

7. Liu, H.; Yang, J.L.; Liu, H. Effect of a viscoelastic target on the impact response of a flat-nosed projectile. Acta Mech. Sin. 2018, 34, 162-174. [CrossRef]

8. El Moumen, A.; Tarfaoui, M.; Hassoon, O.; Lafdi, K.; Benyahia, H.; Nachtane, M. Experimental Study and Numerical Modelling of Low Velocity Impact on Laminated Composite Reinforced with Thin Film Made of Carbon Nanotubes. Appl. Compos. Mater. 2018, 25, 309-320. [CrossRef]

9. Wang, L.L.; Yang, L.M.; Ding, Y.Y. On the energy conservation and critical velocities for the propagation of a "steady-shock" wave in a bar made of cellular material. Acta Mech. Sin. 2013, 29, 420-428. [CrossRef]

10. Xiong, X.; Wang, Z.; Zheng, Y.X. Numerical simulations of Taylor impact experiments of quartz glass bars. Chin. J. Theor. Appl. Mech. 2019, 51, 1082-1090.

11. Xiao, X.K.; Mu, Z.C.; Pan, H.; Lou, Y.S. Effect of the Lode parameter in predicting shear cracking of 2024-T351 aluminum alloy Taylor rods. Int. J. Impact Eng. 2018, 120, 185-201. [CrossRef]

12. Revil-Baudard, B.; Kleiser, G.; Chandola, N.; Cazacu, O. Plastic deformation of metallic materials during dynamic events. J. Phys. Conf. 2018, 1063, 012054. [CrossRef]

13. Hafızoğlu, H.; Durlu, N. Effect of sintering temperature on the high strain rate-deformation of tungsten heavy alloys. Int. J. Impact Eng. 2018, 121, 44-54. [CrossRef]

14. Abed, F.; Jankowiak, T.; Rusinek, A. Verification of a Thermoviscoplastic Constitutive Relation for Brass Material Using Taylor's Test. J. Eng. Mater. Technol. 2015, 137, 041005. [CrossRef]

15. Bigger, R.P.; Carpenter, A.; Scott, N.; Dannemann, K.; Chocron, S.; Williams, C. Dynamic Response of Aluminum 5083 During Taylor Impact Using Digital Image Correlation. Exp. Mech. 2018, 58, 951-961. [CrossRef]

16. Forde, L.C.; Proud, W.G.; Walley, S.M. Symmetrical Taylor impact studies of copper. Proc. Math. Phys. Eng. Sci. 2013, 465, 769-790. [CrossRef]

17. Gao, C.; Iwamoto, T. Finite Element Analysis on a Newly-Modified Method for the Taylor Impact Test to Measure the Stress-Strain Curve by the Only Single Test Using Pure Aluminum. Metals 2018, 8, 642. [CrossRef]

18. Zhong, W.Z.; Rusinek, A.; Jankowiak, T.; Abed, F.; Bernier, R.; Sutter, G. Sutter, Influence of interfacial friction and specimen configuration in Split Hopkinson Pressure Bar system. Tribol. Int. 2015, 90, 1-14. [CrossRef]

19. Zhou, G.Y.; Hu, S.S. Pulse-shaping techniques of high-g-value acceleration generators. Explos. Shock Waves 2013, 33, 479-486.

20. Li, L.; Han, B.; He, S.Y.; Zhao, Z.Y.; Zhang, R.; Zhang, Q.C.; Lu, T.J. Shock loading simulation using density-graded metallic foam projectiles. Mater. Des. 2019, 164, 1-10. [CrossRef]

21. Liu, H.; Zhang, Z.Q.; Liu, H.; Yang, J.L. Effect of elastic target on Taylor-Hopkinson impact of low-density foam material. Int. J. Impact Eng. 2016, 94, 109-119. [CrossRef]

22. Wang, L.L.; Ding, Y.Y.; Yang, L.M. Experimental investigation on dynamic constitutive behavior of aluminum foams by new inverse methods from wave propagation measurements. Int. J. Impact Eng. 2013, 62, 48-59. [CrossRef]

23. Wei-Zhang, C. The analytical solution of G. I. Taylor's theory of plastic deformation in impact of cylindrical projectiles and its improvement. Appl. Math. Mech. 1982, 3, 743-756. [CrossRef] 